\title{
Breastfeeding patterns and exposure to suboptimal breastfeeding among children in developing countries: review and analysis of nationally representative surveys
} Jeremy A Lauer*1, Ana Pilar Betrán², Cesar G Victora3 ${ }^{3}$, Mercedes de Onís ${ }^{4}$ and Aluísio JD Barros 3

Address: ${ }^{1}$ Department of Health System Financing, Expenditure and Resource Allocation, World Health Organization, 1211 Geneva 27 , Switzerland, ${ }^{2}$ Department of Reproductive Health and Research, World Health Organization, 1211 Geneva 27, Switzerland, ${ }^{3}$ Department of Social Medicine, Federal University of Pelotas, C.P. 464 - 96001-970, Pelotas, Brazil and ${ }^{4}$ Department of Nutrition for Health and Development, World Health Organization, 1211 Geneva 27, Switzerland

Email: Jeremy A Lauer* - lauerj@who.int; Ana Pilar Betrán - betrana@who.int; Cesar G Victora - cvictora@terra.com.br; Mercedes de Onís - deonism@who.int; Aluísio JD Barros - abarros@epidemio-ufpel.org.br

* Corresponding author

Published: 01 July 2004

BMC Medicine 2004, 2:26 doi:10.1 186/1741-7015-2-26

This article is available from: http://www.biomedcentral.com/I74I-70I5/2/26

(C) 2004 Lauer et al; licensee BioMed Central Ltd. This is an Open Access article: verbatim copying and redistribution of this article are permitted in all media for any purpose, provided this notice is preserved along with the article's original URL.
Received: 14 October 2003

Accepted: 0 I July 2004

\begin{abstract}
Background: Suboptimal breastfeeding is associated with higher mortality among infants and young children in the developing world. We describe patterns in 'exclusive breastfeeding' and 'any breastfeeding' rates and quantify exposure to suboptimal breastfeeding among children aged two years or younger in developing countries.

Methods: We reviewed nationally representative surveys that collected data on breastfeeding rates in 94 developing countries. Surveys were categorized by completeness and comprehensiveness of data. Complete and comprehensive data were analysed with minimum chi-square regression. With a fitting procedure, estimated parameters were used to impute missing observations for incomplete or non-comprehensive surveys. Breastfeeding indicators were calculated and are reported for I 35 developing countries by UN region.

Results: Amongst infants aged six months or younger in the developing world, the prevalence of exclusive breastfeeding is $39 \%$ and the prevalence of no breastfeeding is $5.6 \%$. The prevalence of continued breastfeeding is $86 \%$ and $68 \%$ for infants and children aged 6-II and 12-23 months, respectively, in the developing world. Imputation expands population coverage of indicators, especially for infants. Breastfeeding trends are highly linear and estimated parameters defining the age-specific attrition hazard are robust. Survey-reported rates, particularly for exclusive breastfeeding, appear to have systematic upward bias, and exposure estimates must be considered conservative.

Conclusions: Compliance with breastfeeding recommendations in developing countries is low, and more attention should be given to increasing breastfeeding - especially exclusive breastfeeding - and to monitoring trends. Although the introduction of more standardized and better validated survey instruments is desirable, since data coverage, completeness and comprehensiveness are extensive, global exposure assessment is relatively robust. Moreover, the regularity of breastfeeding patterns show existing survey data capture real biological and social phenomena. Our method for the analysis of breastfeeding rates provides a potent tool for summarizing trends, validating observations, translating and extrapolating indicators (as well as projecting and imputing estimates when necessary) and should support more effective child health monitoring.
\end{abstract}




\section{Background \\ Objectives}

For almost all infants, breastfeeding remains the simplest, healthiest and least expensive feeding method that fulfils the infant's nutritional needs. The prevalence and duration of breastfeeding are therefore recognized as important health indicators, and their impact on infant and child health has been frequently studied [1-3]. The aim of this study is to describe patterns in 'exclusive breastfeeding' and 'any breastfeeding' rates reported in complete, comprehensive and nationally representative surveys and to quantify exposure to suboptimal breastfeeding in 135 developing countries among children aged two years or younger. 'Suboptimal breastfeeding' is used as a generic term to denote exposure to any increased risk relative to age-specific minimum risk.

\section{Policy background}

Recent policy debate has focused on the optimal duration of exclusive breastfeeding in infancy, and WHO commissioned a systematic review [1] to elucidate the issue. In 2001, the World Health Assembly passed a resolution recommending exclusive breastfeeding for the first six months of life as a global public health recommendation $[1,2]$. International consensus is that optimal breastfeeding practice for infants and young children consists of exclusive breastfeeding for the first six months of life, with continued breastfeeding up to two years of age and beyond $[2,3]$.

\section{Exposure categories}

The term 'category' as used here refers primarily to individual status. For infants $\leq 6$ months of age, exclusive breastfeeding represents 'theoretical minimum' [4] exposure. 'Exclusive breastfeeding' means the infant receives only breast milk from the breast, or expressed breast milk, and receives no other liquids or solids with the exception of drops or syrups consisting of vitamins, mineral supplements or medicines [5].

Ideally, exposure to suboptimal breastfeeding for infants $\leq 6$ months of age would be measured as a continuous variable. Such a variable might express, for example, the proportion of energy, water and nutrients in the diet derived from breast milk. However, since all survey-reported data on breastfeeding are categorical, and in view of the fact that there is heterogeneity in the categories employed, we define two categories: 'partial breastfeeding' and 'no breastfeeding' for the purpose of measuring exposure to increased risk among infants $\leq 6$ months of age. The defining characteristic of partial breastfeeding is that the infant $\leq 6$ months of age receives some breast milk, but not exclusively.
For infants $>6$ months and children $\leq 2$ years of age, theoretical minimum exposure is defined as 'continued breastfeeding', and 'no breastfeeding' is the sole exposure category of increased risk. The defining characteristic of continued breastfeeding is that the infant $>6$ months or child $\leq 2$ years of age receives at least some breast milk regardless of the quantity or the presence of other foods or liquids in the diet. For all infant and child age groups, the defining characteristic of 'no breastfeeding' is that the infant or child receives no breast milk.

For analysis purposes we further define the category 'any breastfeeding', which refers to infants or children receiving breast milk regardless of quantity or the presence of other foods or liquids in the diet. For infants $\leq 6$ months of age, 'any breastfeeding' is equivalent to the category 'exclusive or partial breastfeeding', and for infants $>6$ months and children $\leq 2$ years of age is identical to the category 'continued breastfeeding'. For children $>2$ years of age analysed in subregional estimation models, 'any breastfeeding' is used merely as a descriptive category without regard to risk status.

For infants $>6$ months of age, the failure to provide safe and appropriate complementary foods has been identified as a risk factor. We do not investigate this exposure in the present study.

\section{Breastfeeding indicators}

For population-level assessment, exposure categories are aggregated across individuals and expressed as indicators. Therefore, breastfeeding indicators, in the sense used here, are primarily summary measures of population-level exposure with direct relevance for health outcomes. Although many types of indicator are in common use, the breastfeeding indicators reported here are measures of cross-sectional prevalence for the defined exposure categories and age ranges. Cross-sectional prevalence is also called 'point prevalence' or 'period prevalence'.

Since surveys include prevalence estimates for states that may only indirectly be a measure of exposure according to our definitions, some of our indicators (complex indicators) represent sums of other indicators. For example, partial breastfeeding represents an aggregation of survey feeding categories such as 'breast milk plus formula', 'breast milk plus solid foods', 'predominant breastfeeding', and so on. Continued breastfeeding likewise represents an aggregation of various indicators. However, exclusive breastfeeding and no breastfeeding are simple, not complex, indicators.

\section{Breastfeeding and HIV}

Breastfeeding for more than one year has been estimated to pose a $10-20 \%$ risk of HIV transmission in children of 
infected mothers [6]. The risk of HIV transmission needs to be balanced, however, against competing risks for infant mortality and morbidity. WHO states that 'when replacement feeding is acceptable, feasible, affordable, sustainable and safe, avoidance of all breastfeeding by HIV-positive women is recommended; otherwise, exclusive breastfeeding is recommended during the first months of life; and that those who choose other options should be encouraged to use them free from commercial influences' $[6,7]$.

Since recommended practice depends on mothers' HIV status and other individual factors, only an individuallevel assessment can explicitly account for the offsetting risks posed by mother-to-child transmission of HIV through breastfeeding. The population-level indicators reported here cannot measure this risk in a manner consistent with current international infant-and-child-feeding recommendations. In a related study, we use an outcomes-based assessment to estimate the potential magnitude of the risks of mother-to-child transmission of HIV through breastfeeding (results not shown).

\section{Methods}

\section{Data sources}

Data sources are nationally representative surveys - published and unpublished - that we identified as of June 2002 with data on breastfeeding in 94 developing countries. Most surveys were undertaken by the Demographic and Health Surveys (DHS) programme of Macro International, Calverton, MD, USA [8], or by UNICEF under its initiative on Multiple Indicators Cluster Surveys (MICS) [9]. About a dozen surveys were undertaken by national institutions.

For developing countries with more than one survey, the most recent was used for calculating breastfeeding indicators, but all available complete, comprehensive and nationally representative surveys that we identified were used for estimating patterns in exclusive and any breastfeeding rates. The Annex to this article (Additional file 1) presents a list of the developing countries for which data were identified, the data source used for the indicators we report, and the corresponding survey year and data category (see below).

DHS surveys report prevalence estimates for various breastfeeding indicators for children in 18 two-month age groups through the end of the third year of life $(0-1, \ldots$, 34-35 months of age). DHS estimates are based on 24hour recall, in which mothers or caregivers are asked about the infant or child's food and fluid intake during the 24-hour period preceding the interview. Because of the wide age range (comprehensiveness, or coverage in breadth), fine age stratification (completeness, or cover- age in depth) and use of comparable feeding categories, DHS survey data on breastfeeding are the most complete and comprehensive, and we consider them the most reliable. They are also nationally representative. Data from DHS surveys are termed 'category A'. About $78 \%$ of the surveys used for calculating breastfeeding indicators are category A.

MICS surveys report prevalence estimates only for selected indicators, such as 'exclusive breastfeeding, 0-3 months of age', and are not as consistent as DHS surveys in covering either a given set of age groups or a given age range. Consequently, MICS data required imputation or extrapolation (see below) of missing observations of twomonth prevalence for analysis on a comparable basis with those of DHS. Like DHS, MICS surveys employ 24-hour recall, but use a questionnaire superior in some respects to those of DHS surveys (see Discussion, 24-hour recall). However, we found some evidence of low internal validity in MICS surveys, although this impression could be due merely to otherwise benign typographical errors in reports. Data from MICS surveys are considered 'category B'.

Other, non-standard, surveys report various breastfeeding indicators estimated with diverse methods for a variety of age groups. When such data were nationally representative they were included, but required imputation of missing observations of two-month prevalence for analysis on a comparable basis with those of DHS. A few surveys with data reported as cohort rather than period measures additionally required translation (see below) prior to imputation. Although it is possible that non-standard surveys are less reliable than MICS, since there was no obvious reason to conclude this, and since the sort of analysis they required for comparability with DHS surveys was similar to that required for MICS, non-standard surveys are also considered 'category B'.

Surveys with potential category-B data were not included unless they contained at least one observation of either exclusive, any or no breastfeeding. About $22 \%$ of the surveys used for calculating breastfeeding indicators are category $\mathrm{B}$, with about half non-standard, and half MICS. The term for the implicit data category for countries with no nationally representative data on breastfeeding is 'category $C^{\prime}$. As shorthand, we refer to countries with category$\mathrm{A}, \mathrm{B}$ or $\mathrm{C}$ data as category-A, B or C countries, respectively.

Available data for infants were category A in 75 countries; for children 12-23 months of age, data were category A in 73 countries. Available data for infants were category B in 19 countries; for children 12-23 months of age, data were category B in 11 countries. A total of 41 countries were 
Table I: Prevalence estimates for breastfeeding indicators, by subregion and age group

\begin{tabular}{|c|c|c|c|c|c|c|c|}
\hline \multirow{3}{*}{$\begin{array}{l}\text { Region } \\
\text { Subregion }\end{array}$} & \multicolumn{7}{|c|}{ Breastfeeding indicator estimates (\%) } \\
\hline & \multicolumn{3}{|c|}{ Infants $<6$ months of age } & \multicolumn{2}{|c|}{ Infants 6-II months of age } & \multicolumn{2}{|c|}{ Children I 2-23 months of age } \\
\hline & Exclusive & Partial & No & Continued & No & Continued & No \\
\hline Africa & 24.9 & 71.2 & 3.9 & 91.8 & 8.2 & 69.9 & 30.1 \\
\hline Eastern & 41.4 & 56.1 & 2.4 & 95.1 & 4.9 & 75.6 & 24.4 \\
\hline Middle & 19.4 & 79.6 & 1.0 & 96.6 & 3.4 & 76.8 & 23.2 \\
\hline Northern & 36.5 & 53.9 & 9.6 & 77.7 & 22.3 & 49.6 & 50.4 \\
\hline Southern & 8.2 & 75.7 & 16.0 & 70.4 & 29.6 & 46.7 & 53.3 \\
\hline Western & 6.1 & 92.1 & 1.8 & 96.8 & 3.2 & 74.9 & 25.1 \\
\hline Asia (excluding Japan) & 44.9 & 50.7 & 4.5 & 87.5 & 12.5 & 72.4 & 27.6 \\
\hline Eastern & 58.6 & 36.3 & 5.1 & 85.7 & 14.3 & $N D^{a}$ & ND \\
\hline South-Central & 42.1 & 55.3 & 2.6 & 93.3 & 6.7 & 78.8 & 21.2 \\
\hline South-Eastern & 37.5 & 55.0 & 7.5 & 76.7 & 23.3 & 61.7 & 38.3 \\
\hline Western & 17.7 & 72.0 & 10.3 & 71.3 & 28.7 & 37.3 & 62.7 \\
\hline Latin America and the Caribbean & 30.8 & 51.2 & 18.0 & 59.9 & 40.1 & 36.5 & 63.5 \\
\hline Caribbean & 25.8 & 63.8 & 10.4 & 64.6 & 35.4 & 34.2 & 65.8 \\
\hline Central America & 23.4 & 55.0 & 21.6 & 60.2 & 39.8 & 37.0 & 63.0 \\
\hline South America & 35.1 & 48.0 & 16.9 & 59.3 & 40.7 & 36.4 & 63.6 \\
\hline Developing countries ${ }^{b}$ & 38.7 & 55.7 & 5.6 & 85.8 & 14.2 & 68.3 & 31.7 \\
\hline
\end{tabular}

a ND = no data. ${ }^{b}$ The region Oceania (including developing countries Guam, Fiji, French Polynesia, New Caledonia, Papua New Guinea, Samoa, Solomon Islands and Vanuatu) was excluded, as nationally representative breastfeeding data were not available for any developing countries in Oceania.

category C for infants; for children 12-23 months of age, 51 countries were category $\mathrm{C}$.

\section{Reporting regions}

The 135 developing countries were grouped according to the UN regional and subregional classification (see Table 1) [10]. Japan was excluded from regional and subregional estimates for Asia. The region Oceania (including developing countries Guam, Fiji, French Polynesia, New Caledonia, Papua New Guinea, Samoa, Solomon Islands and Vanuatu) was excluded, as no nationally representative breastfeeding data were obtained for any developing countries in Oceania.

\section{Analysis regions}

Although UN regions are geographical designations only, WHO has developed a subregional classification on the basis of both geographical and epidemiologic criteria. The 14 subregions represent a classification of countries in the six WHO regions according to four possible patterns of child and adult mortality [11]. Since no WHO region presents more than three of the defined patterns, there are substantially fewer than the theoretically possible 24 subregions.

The mortality patterns used in the classification are defined so as to locate a country with regard to the epidemiologic transition, and therefore represent a macro-level classification of conditions affecting demography, development and proportional causes of death $[12,13]$. For estimating age trends in exclusive and any breastfeeding rates, we used a stratification defined by the nine WHO subregions found in the developing world.

\section{Basic calculation of indicators}

Basic calculation methods described in this section were used to calculate indicators for category-A countries. Other countries first required either imputation of missing observations or extrapolation or, occasionally, translation of observations prior to calculation of indicators.

Country indicators for no breastfeeding were calculated as weighted averages of reported estimates of the cross-sectional prevalence of no breastfeeding for two-month age groups by summing over the relevant age ranges $(0-5,6-$ 11 and 12-23 months of age) with population weights. Population weights for aggregation across age ranges (aggregation within category-A countries) were calculated using the numbers of infants or children surveyed in each two-month age group. The country indicator for exclusive breastfeeding for infants $\leq 6$ months of age was similarly calculated as a weighted average of the cross-sectional country prevalence of exclusive breastfeeding for twomonth age groups over the range $0-5$ months of age. 
The country indicator for partial breastfeeding for infants $\leq 6$ months of age was calculated as $100 \%$ - (\%Exclusive breastfeeding $+\%$ No breastfeeding), where '\%Exclusive breastfeeding' and '\%No breastfeeding' are the country indicators (expressed as percentages) for exclusive and no breastfeeding, respectively, for the age range 0-5 months. For infants $>6$ months and $\leq 2$ years of age, the country indicator for continued breastfeeding for each age range (6-11 and 12-23 months of age) was calculated as 100\% - \%No breastfeeding, where '\%No breastfeeding' is the country indicator for no breastfeeding for the relevant age range.

Regional breastfeeding indicators were calculated as infant-population weighted averages of country indicators (aggregation between category-A countries). Estimates of infant population are based on figures published by the United Nations [13]. Weights calculated with country infant populations were also used to calculate regional indicators for children 12-23 months of age.

\section{Subregional estimation models}

We used subregional regression models to estimate age trends in exclusive and any breastfeeding rates for category-A countries. The models are stratified by the nine WHO subregions found in the developing world. Subregion-specific results were used to impute missing observations of breastfeeding rates for category-B countries in the corresponding subregions. We refer to any estimation, imputation, extrapolation, translation or projection as 'analysis'.

Breastfeeding rates were transformed with the logit function prior to analysis [14]. The logit of breastfeeding rate $p$ is $\log (p / 1-p)$, where $p$ is a proportion (that is, $p=\%$ Rate/ $100)$. For data where, as here, country-specific observations of $p$ are available only for defined age groups, and where the dependent variable represents a dichotomous response, minimum chi-square regression, also called Berkson-Theil weighted least squares, yields unbiased, minimum-variance estimates of regression betas [14].

The regression equation is:

$\log (p / 1-p)=a+b x+\varepsilon, \quad$ Equation 1

where $p$ is the breastfeeding rate, $x$ is month of age, $a$ and $b$ are the parameters to estimate (regression betas) and $\varepsilon$ is the error term. Regressions were run separately for exclusive and any breastfeeding rates in each of the nine subregions. Parameter estimates were used to predict breastfeeding rates by solving the regression equation for $p$ :

$$
\hat{p}=\frac{\operatorname{Exp}(\hat{b}+\hat{a} x)}{1+\operatorname{Exp}(\hat{b}+\hat{a} x)} .
$$

Equation 2

The regression equation implies $p$ is a logistic function of age.

A linear model for the logit of prevalence is equivalent to a log-linear model for prevalence odds. The log-linear odds model is one of the most common in epidemiology [15], but its use is often justified on merely pragmatic grounds [16]. However, on the assumption that breastfeeding attrition rates continually decrease (that is, become more negative) with age, the logarithm of breastfeeding prevalence odds is constrained to be linear, implying the logit model is correctly specified for estimation of regression betas (results not shown).

\section{Imputation}

The parameters $(a, b)$ estimated for category-A countries were the starting point for imputing missing observations of two-month prevalence for category-B countries in the same subregion. The first step was to calibrate (by changing the intercept, $b$, or by changing the slope, $a$, and the intercept, $b$ ) the subregional category-A trend line so as to fit available observations of the breastfeeding rate in the desired category-B country in a least-squares sense. Secondly, missing observations of breastfeeding prevalence in the desired category-B country were predicted with the calibrated trend line. Finally, indicators were calculated for the desired category-B country using the basic calculation methods described above, with the difference that population weights were calculated on the basis of the country's infant mortality rate.

For example, suppose country $\mathrm{X}$ in subregion $\mathrm{Y}$ has category-B data consisting of an observation of cross-sectional prevalence of exclusive breastfeeding of $16 \%$ for infants 0-3 months of age. The observed prevalence can be considered as a weighted average of two unobserved prevalences, for infants $0-1$ and 2-3 months of age, respectively. Now suppose the subregional trend for category-A countries in subregion Y predicts (after back-transformation with the logistic function) a cross-sectional prevalence of $44 \%$ exclusive breastfeeding for infants $0-1$ months of age and 34\% for infants 2-3 months of age. Applying population weights calculated with country X's infant mortality rate (aggregation within category-B countries), the two predictions imply a predicted cross-sectional prevalence of exclusive breastfeeding of $40 \%$ for infants 0-3 months of age.

Keeping the slope of the estimated trend constant, the intercept is changed until the predicted prevalence of exclusive breastfeeding for infants $0-3$ months of age in 
country $\mathrm{X}$ is $16 \%$, as observed. Following calibration of the trend line to country $\mathrm{X}$ 's observation, it was possible to predict the prevalence of exclusive breastfeeding for infants 4-5 months of age using the new intercept, $b$ '. Again applying population weights calculated with country X's infant mortality rate, the three predicted prevalences of exclusive breastfeeding are summed, yielding an imputed estimate for the exclusive breastfeeding indicator for country X.

Now suppose country X has additional category-B data consisting, for example, of an observation of the cross-sectional prevalence of no breastfeeding of $18 \%$ for infants $\leq 6$ months of age. Taking $100 \%-18 \%$ yields an estimate of any breastfeeding of $82 \%$ for infants $\leq 6$ months of age. Now suppose the trend for category-A countries in subregion $\mathrm{Y}$ predicts a cross-sectional prevalence of $76 \%$ any breastfeeding for infants $0-1,70 \%$ for infants $2-3$, and $64 \%$ for infants $4-5$ months of age. Applying population weights calculated with country X's infant mortality rate, the three predictions imply a cross-sectional prevalence of $70 \%$ any breastfeeding for infants $\leq 6$ months of age, which is the same as an estimated prevalence of $30 \%$ no breastfeeding for the age group.

Keeping the slope of the estimated trend constant, the intercept is changed until the predicted prevalence of any breastfeeding for infants $\leq 6$ months of age in country $\mathrm{X}$ is $82 \%$ (corresponding to a predicted prevalence of no breastfeeding of $18 \%$, as observed). With the new intercept, $b^{\prime}$, and population weights calculated for the corresponding two-month age groups, it is possible to impute the prevalence of no breastfeeding for infants 6-11 months of age, as well as for children 12-23 months of age.

When, as in the above example, available data for country $\mathrm{X}$ contain only one observation of exclusive and no breastfeeding, it is possible to fit the observed prevalence exactly by changing the intercept of the estimated subregional trend. However, if country $\mathrm{X}$ has two or more observations of prevalence for a breastfeeding category, in general it will not be possible to fit all observations exactly. In such a case, it was necessary to change both the slope and the intercept to fit available observations. Here, again, although with two observations it is possible to fit them exactly by changing two parameters, if more observations are available, generally it will not be possible to fit them all exactly. When such cases arose, a least-squares approach was used, whereby the parameter values that best fit, in the least-squares sense, all available observations were chosen.

Note that the slope parameter estimates the rate of change of the logit of prevalence, while the intercept estimates the logit of prevalence at 0 months of age. We made the arbitrary decision that it was preferable to change the intercept. Therefore, as a rule of thumb, when it was necessary to change both parameters, the intercept was changed first to fit the observations as nearly as possible before changing the slope. If necessary, this two-step (intercept then slope) fitting procedure was repeated until a defined tolerance level (that is, sum of squared deviations less than a given threshold) was satisfied.

Once all available observations for country $\mathrm{X}$ were fit either exactly or in the least squares sense - with the trend line thus calibrated it was possible to predict a complete and comprehensive series of cross-sectional prevalence for exclusive and any breastfeeding. However, if, in a given country, observations were available for only one rate (exclusive or any), the estimated subregional trend was used without adjustment to predict the other. In any case, once predictions were available for both exclusive and any breastfeeding, it was possible to predict rates of partial and continued breastfeeding by relying on the fact that, for infants $\leq 6$ months of age, the percentages of exclusive, partial and no breastfeeding must add to $100 \%$, and, for infants 6-11 and children 12-23 months of age, percentages of continued and no breastfeeding must add to $100 \%$.

Country estimates of indicators calculated with predictions deriving from subregional estimation, whether or not a subsequent fitting procedure was performed, are called imputed indicators. To impute indicator estimates for category- $\mathrm{C}$ countries, the subregional averages calculated on the basis of both category-A and category-B countries were used without adjustment.

\section{Extrapolation}

If enough observations were available for a category-B country, it was possible to estimate a country-specific trend line. In such cases, observed rates were extrapolated by means of a regression on age for that country alone, and the resulting series of predicted rates was averaged with population weights to obtain estimates of indicators. Because it relies on a country's own data, this procedure is called extrapolation in order to distinguish it from imputation (applying estimates based on other countries' data). Depending on available data, a country might have extrapolated estimates for one rate (exclusive or any) and imputed estimates for the other.

\section{Translation between cohort and period indicators}

DHS and similar surveys report estimates of cross-sectional (period) prevalence for two-month age groups. However, in a few countries, estimates were reported in longitudinal (cohort) terms, that is, as the proportion of a birth cohort remaining in a category at a specific age. Prior 
to analysis, longitudinal estimates were translated into cross-sectional ones by assuming the implicit cohort attrition rate applied to the other infant and child cohorts in the population, and averaging the resulting series with population weights calculated on the basis of the country's infant mortality rate. Since translation yields a complete but not comprehensive series of predictions, extrapolation or imputation was performed to obtain the series of predictions required for calculation of indicators.

\section{Uncertainty}

A random-effects model (that is, with country-specific random effects) can be used to obtain estimates for the standard error of regional estimates of breastfeeding indicators based on category-A country data. However, the kind of error analysed with a random-effects (or similar) model is that arising from observing only part of the entire population, and is termed statistical error. Depending on the validity of the survey methods and responses, category-A data may also involve systematic measurement error.

Indicators based on category-B or $\mathrm{C}$ data involve a further source of uncertainty deriving from use of the subregional estimation model, and also, in the case of category B, the validity and statistical error of available data. Reported indicators therefore potentially involve statistical, model and measurement error, which interact non-linearly. Model error and measurement error are not captured by random-effects estimates, and there is no general analytical method capable of taking account of these sources of error.

\section{Results \\ Indicator estimates}

Table 1 shows cross-sectional prevalence estimates for breastfeeding indicators by UN region. Exclusive breastfeeding rates are low, at about 25\% in Africa, 45\% in Asia and $31 \%$ in Latin America and the Caribbean, or 39\% of infants $\leq 6$ months of age in developing countries. However, most of the infant population in developing countries is receiving some breast milk, as the prevalence of no breastfeeding is only $5.6 \%$ for infants, ranging from about $4 \%$ in Africa to $18 \%$ in Latin America and the Caribbean. The prevalence of continued breastfeeding is about $86 \%$ for infants 6-11 months of age in the developing world, and ranges from $92 \%$ and $88 \%$ in Africa and Asia, respectively, to $60 \%$ in Latin America and the Caribbean. For children 12-23 months of age, the prevalence of continued breastfeeding drops to about $70 \%$ and $72 \%$ in Africa and Asia, respectively, and to $37 \%$ in Latin America and the Caribbean.
Uncertainty analysis performed with the random-effects model yielded confidence intervals on the order of 1-2 percentage points for each indicator (results not shown).

\section{Population coverage of indicators}

The distribution of age-specific population by data category in each UN region is shown in Table 2. In Africa and Latin America/the Caribbean, about $80 \%$ and $91 \%$ of the infant population, respectively, was covered with category-A data. In Asia $64 \%$ of the infant population was covered with category-A data.

For children 12-23 months of age, $86 \%$ of the population in Latin America and the Caribbean was covered with category-A data, as was 79\% in Africa and 59\% in Asia. For developing countries, $70 \%$ of infants and $67 \%$ of children 12-23 months of age were covered with category-A data.

When category-B data are considered, population coverage in developing countries increases to $95 \%$ for infants (representing about 106 million infants worldwide) and $73 \%$ for children 12-23 months of age. Inclusion of category-B data increases population coverage most in Africa (for both infants and children 12-23 months of age) and Asia (for infants only). Lack of data for China on children 12-23 months of age substantially limits population coverage in Asia for that age group.

\section{Subregional estimation models}

Selected results for the subregional estimation models are presented in Tables 3 and 4 and Figures 1, 2, 3, 4, 5, 6, 7, 8,9 . These figures show estimated age trends for exclusive breastfeeding for the age groups $0-1$ to 8-9 months of age (upper panels; reference line, $1 \%$ prevalence), and for any breastfeeding for the age groups $0-1$ to 22-23 months of age (lower panels; reference line, 15\% prevalence). Regressions use minimum chi-square estimation with dependent variable the logarithm of prevalence odds (that is, $\log (p / 1-p)$, where $p$ is prevalence of the breastfeeding indicator), and independent variable the oldest month of age by two-month age group; exclusive breastfeeding was estimated for five age groups $0-1$ to 8-9 months of age, any breastfeeding for 18 age groups $0-1$ to 34-35 months of age (shown only for children $\leq 2$ years of age); $n$ is the number of pooled observations; inverse-variance weights -used in estimation are shown by the relative size of data markers; regressions for category-A countries are stratified by geographical and epidemiologic criteria as noted in the figure legends. Data sources are listed in the Annex (Additional file 1).

For almost all countries, the logit transformation reduced a markedly non-linear age trend to one well described by the estimated slope and constant (Figure 10). Some countries are systematically over- or under-predicted by the 
Table 2: Population coverage by subregion, age group and data category

\begin{tabular}{|c|c|c|c|c|c|c|c|c|}
\hline \multirow{3}{*}{$\begin{array}{l}\text { Region } \\
\text { Subregion }\end{array}$} & \multicolumn{4}{|c|}{ Infants aged $0-1 /$ months } & \multicolumn{4}{|c|}{ Children aged I2-23 months } \\
\hline & \multirow[t]{2}{*}{ Population with data (\%) } & \multicolumn{3}{|c|}{ Category } & \multirow[t]{2}{*}{ Population with data (\%) ${ }^{\mathrm{a}}$} & \multicolumn{3}{|c|}{ Category } \\
\hline & & $\mathbf{A}$ & B & C & & $\mathbf{A}$ & B & C \\
\hline Africa & 99.1 & 79.5 & 19.6 & 0.9 & 97.6 & 79.2 & 18.4 & 2.4 \\
\hline Eastern & 99.4 & 91.8 & 7.6 & 0.6 & 99.4 & 91.8 & 7.6 & 0.6 \\
\hline Middle & 96.5 & 25.9 & 70.6 & 3.5 & 96.5 & 25.9 & 70.6 & 3.5 \\
\hline Northern & 99.8 & 52.3 & 47.5 & 0.2 & 95.1 & 57.2 & 37.9 & 4.9 \\
\hline Southern & 95.1 & 91.5 & 3.6 & 4.9 & 95.1 & 91.5 & 3.6 & 4.9 \\
\hline Western & 100 & 100 & 0 & 0 & 97.9 & 96.7 & 1.2 & 2.1 \\
\hline Asia (excluding Japan) & 93.5 & 63.5 & 30.0 & 6.5 & 62.0 & 59.4 & 2.5 & 38.0 \\
\hline Eastern & 94.1 & 0 & 94.1 & 5.9 & 0 & 0 & 0 & 100 \\
\hline South-Central & 97.3 & 97.3 & 0 & 2.7 & 90.9 & 90.9 & 0 & 9.1 \\
\hline South-Eastern & 84.6 & 74.5 & 10.1 & 15.4 & 84.7 & 74.5 & 10.1 & 15.4 \\
\hline Western & 83.6 & 65.1 & 18.5 & 16.4 & 65.2 & 50.3 & 14.9 & 34.8 \\
\hline Latin America and the Caribbean & 92.6 & 91.2 & 1.4 & 7.4 & 86.2 & 86.2 & 0 & 13.8 \\
\hline Caribbean & 84.9 & 77.3 & 7.6 & 15.1 & 84.9 & 84.9 & 0 & 15.1 \\
\hline Central America & 98.2 & 95.6 & 2.6 & 1.8 & 98.2 & 98.2 & 0 & 1.8 \\
\hline South America & 90.8 & 90.6 & 0.2 & 9.2 & 80.6 & 80.6 & 0 & 19.4 \\
\hline Developing countries ${ }^{b}$ & 94.8 & 70.1 & 24.7 & 5.2 & 72.9 & 66.8 & 6.1 & 27. 1 \\
\hline
\end{tabular}

Percentage of infant and child population in each region for which there were complete and comprehensive (category A), incomplete or noncomprehensive (category B) or no (category C) data on breastfeeding. a Includes categories A and B. b The region Oceania (including developing countries Guam, Fiji, French Polynesia, New Caledonia, Papua New Guinea, Samoa, Solomon Islands and Vanuatu) was excluded, as nationally representative breastfeeding data were not available for any developing countries in Oceania.

Table 3: Summary regression results for age trends for exclusive breastfeeding

\begin{tabular}{lllll}
\hline $\begin{array}{l}\text { Stratum } \\
\text { name }\end{array}$ & Stratum characteristics & $\begin{array}{l}\text { Intercept (95\% } \\
\text { confidence interval) }\end{array}$ & $\begin{array}{l}\text { Slope (95\% confidence } \\
\text { interval) }\end{array}$ & $\begin{array}{l}\text { Standard error of the } \\
\text { residual }\end{array}$ \\
\hline AfrD & Africa: high adult, high child mortality & $-0.98(-1.33,-0.63)$ & $-0.21(-0.29,-0.14)$ & 1.66 \\
AfrE & Africa: very high adult, high child mortality & $0.68(0.29,1.07)$ & $-0.38(-0.47,-0.29)$ & 1.79 \\
AmrB & Americas: low child, low adult mortality & $0.23(-0.20,0.66)$ & $-0.39(-0.50,-0.29)$ & 1.14 \\
AmrD & Americas: high adult, high child mortality & $0.91(0.47,1.34)$ & $-0.39(-0.49,-0.28)$ & 1.10 \\
EmrB & $\begin{array}{l}\text { Eastern Mediterranean: low child, low adult } \\
\text { mortality }\end{array}$ & $-0.84(-1.75,0.06)$ & $-0.47(-0.80,-0.14)$ & 0.57 \\
EmrD & $\begin{array}{l}\text { Eastern Mediterranean: high adult, high child } \\
\text { mortality }\end{array}$ & $0.26(-0.25,0.76)$ & $-0.29(-0.39,-0.18)$ & 0.90 \\
SearB & $\begin{array}{l}\text { South-east Asia: low child, low adult } \\
\text { mortality }\end{array}$ & $1.01(0.55,1.48)$ & $-0.47(-0.58,-0.35)$ & 0.92 \\
SearD & $\begin{array}{l}\text { South-east Asia: high adult, high child } \\
\text { mortality }\end{array}$ & $1.03(0.83,1.23)$ & $-0.38(-0.42,-0.33)$ & 0.63 \\
WprB & $\begin{array}{l}\text { Western Pacific: low child, low adult } \\
\text { mortality }\end{array}$ & $0.58(-0.15,1.31)$ & $-0.45(-0.68,-0.22)$ & 1.49 \\
\hline
\end{tabular}

Regressions use minimum chi-square estimation with dependent variable logarithm of prevalence odds (that is, Log( $p / I$ - $p$ ), where $p$ is prevalence of exclusive breastfeeding), and independent variable oldest month of age by two-month age groups; regressions for category-A countries stratified by geographical and epidemiologic criteria as noted in the table; exclusive breastfeeding estimated for five age groups 0-1 to 8-9 months of age.

Data sources listed in the Annex (Additional file I). 
Table 4: Summary regression results for age trends for any breastfeeding

\begin{tabular}{|c|c|c|c|c|}
\hline $\begin{array}{l}\text { Stratum } \\
\text { name }\end{array}$ & Stratum characteristics & $\begin{array}{l}\text { Intercept }(95 \% \\
\text { confidence interval) }\end{array}$ & $\begin{array}{l}\text { Slope }(95 \% \text { confidence } \\
\text { interval) }\end{array}$ & $\begin{array}{l}\text { Standard error of the } \\
\text { residual }\end{array}$ \\
\hline AfrD & Africa: high adult, high child mortality & $4.28(4.05,4.51)$ & $-0.20(-0.21,-0.19)$ & 1.30 \\
\hline AfrE & Africa: very high adult, high child mortality & $4.71(4.43,5.00)$ & $-0.20(-0.21,-0.18)$ & 1.12 \\
\hline AmrB & Americas: low child, low adult mortality & $1.34(1.16,1.52)$ & $-0.12(-0.13,-0.11)$ & 0.79 \\
\hline AmrD & Americas: high adult, high child mortality & $3.57(3.29,3.86)$ & $-0.18(-0.20,-0.17)$ & 0.83 \\
\hline EmrB & $\begin{array}{l}\text { Eastern Mediterranean: low child, low adult } \\
\text { mortality }\end{array}$ & $2.85(2.58,3.12)$ & $-0.22(-0.23,-0.20)$ & 0.36 \\
\hline EmrD & $\begin{array}{l}\text { Eastern Mediterranean: high adult, high child } \\
\text { mortality }\end{array}$ & $3.40(3.16,3.64)$ & $-0.17(-0.18,-0.16)$ & 0.80 \\
\hline SearB & $\begin{array}{l}\text { South-east Asia: low child, low adult } \\
\text { mortality }\end{array}$ & $3.58(3.36,3.79)$ & $-0.14(-0.15,-0.13)$ & 0.49 \\
\hline SearD & $\begin{array}{l}\text { South-east Asia: high adult, high child } \\
\text { mortality }\end{array}$ & $4.03(3.72,4.34)$ & $-0.14(-0.15,-0.12)$ & 0.89 \\
\hline WprB & $\begin{array}{l}\text { Western Pacific: low child, low adult } \\
\text { mortality }\end{array}$ & $2.18(1.77,2.60)$ & $-0.14(-0.16,-0.12)$ & 2.77 \\
\hline
\end{tabular}

Regressions use minimum chi-square estimation with dependent variable logarithm of prevalence odds (that is, $\log (p / I-p)$, where $p$ is prevalence of any breastfeeding), and independent variable oldest month of age by two-month age groups; regressions for category-A countries stratified by geographical and epidemiologic criteria as noted in the table; any breastfeeding estimated for I8 age groups 0-I to 34-35 months of age. Data sources listed in the Annex (Additional file I).

subregional trend, but still show highly linear patterns (Figure 11). Although for a small group of countries systematic non-linearity remained (Figure 12), at the subregional level the linear component, as measured by the $F$ statistic (results not shown), was always strongly significant.

Some countries showed highly variable observations month by month, which is suggestive of the limitations of 24-hour recall or the presence of systematic measurement error (Figure 13). These anomalies were particularly evident in observations of exclusive breastfeeding at older ages (Figures 14, 15, 16, 17).

Analysis of Equation 2, the logistic expression for prevalence, shows that the regression betas $(a, b)$ fully define the attrition hazard for the corresponding breastfeeding rate as a function of age (results not shown). The average hazards for exclusive (upper panel) and any (lower panel) breastfeeding are displayed in Figure 18 versus month of age.

\section{Discussion \\ 24-hour recall}

An assessment based on 24-hour recall will not always represent true exposure status, since infants may change feeding practices when ill or during the absence of the mother. In particular, 24-hour recall will generate a large number of false positives for exclusive breastfeeding [17]. This conclusion is supported by results from communitybased studies $[18,19]$. Other studies have found that infants classified as exclusively breastfeeding with 24- hour recall receive other liquids and even solid foods on a less-than-daily basis $[17,20]$.

In a prospective analysis published in 2000 , the difference between data from 24-hour recall and those from mothers' daily records was compared, and it was found that 24hour recall overestimated exclusive breastfeeding rates by an absolute magnitude of about $40 \%$ percentage points at both two and four months of age ( $92 \%$ versus $51 \%$ at two months, and $73 \%$ versus $30 \%$ at four months of age) [21]. The most common reason for misclassification was the consumption of water or water-based drinks. Infants receiving water or water-based drinks in addition to breast milk are referred to as 'predominantly breastfed'.

The study shows infants whose true status is 'predominant' are frequently classified as 'exclusive' with 24-hour recall. Consistent with international recommendations, only infants not receiving water or water-based drinks should be classified as exclusive, and studies have shown that the introduction of any fluids other than breast milk is associated with increased risk of morbidity and mortality [22-24]. Since data from the same study show that about $30 \%$ of infants classified as 'exclusive' or 'predominant' receive some solid-food supplements, it appears there is a significant tendency to under-report small-quantity items administered in addition to breast milk.

An additional cause of overestimation is the use of filter questions. In many surveys, including DHS, the mother is asked 'For how long have you given your child only the breast?'. Although instructions following the question 


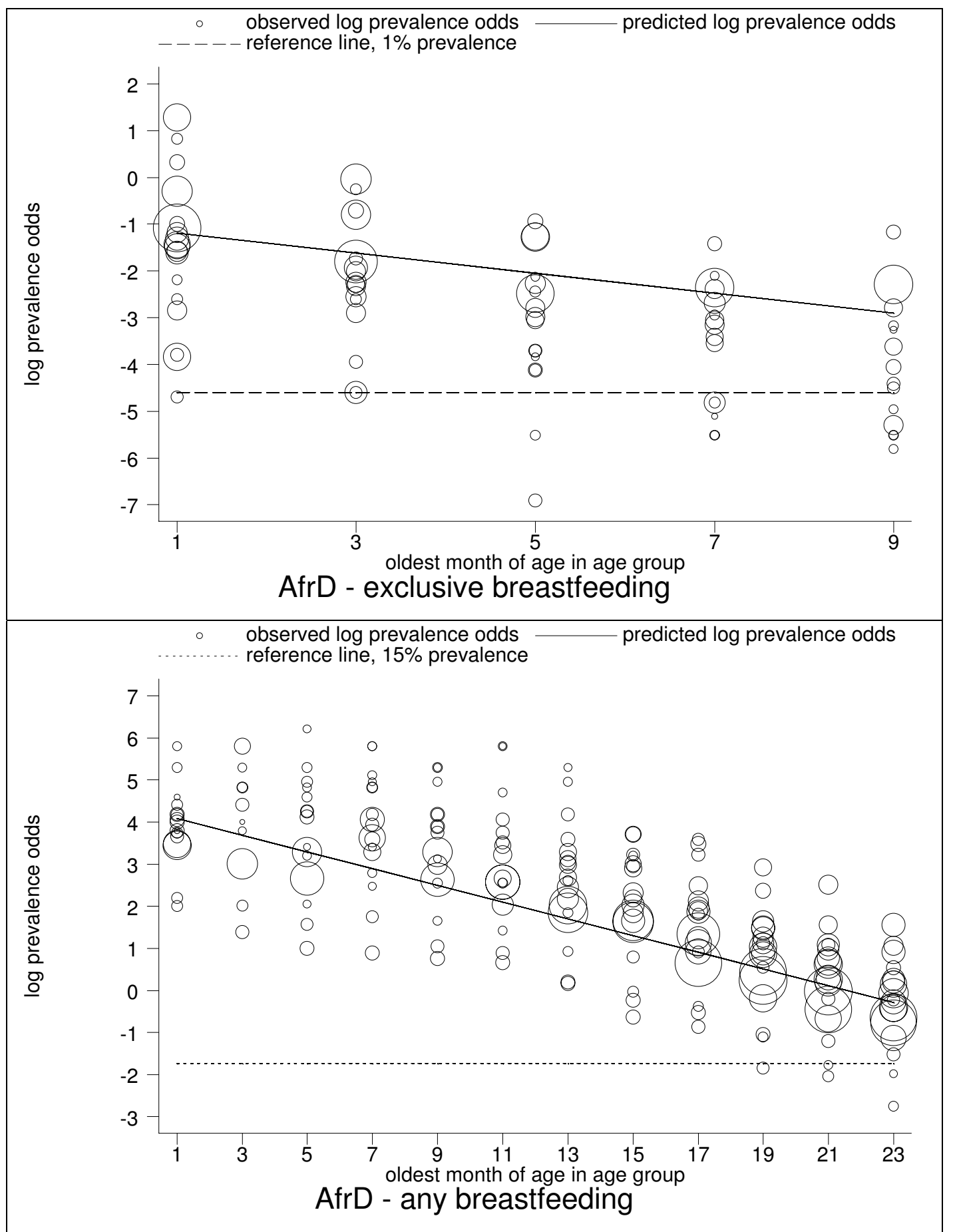

\section{Figure I}

Estimated age trends for exclusive breastfeeding and for any breastfeeding in AfrD (Africa: high-adult, high-child-mortality stratum). Exclusive breastfeeding (upper panel, $n=8 \mathrm{I}$ ), any breastfeeding (lower panel, $n=30 \mathrm{I}$ ). 


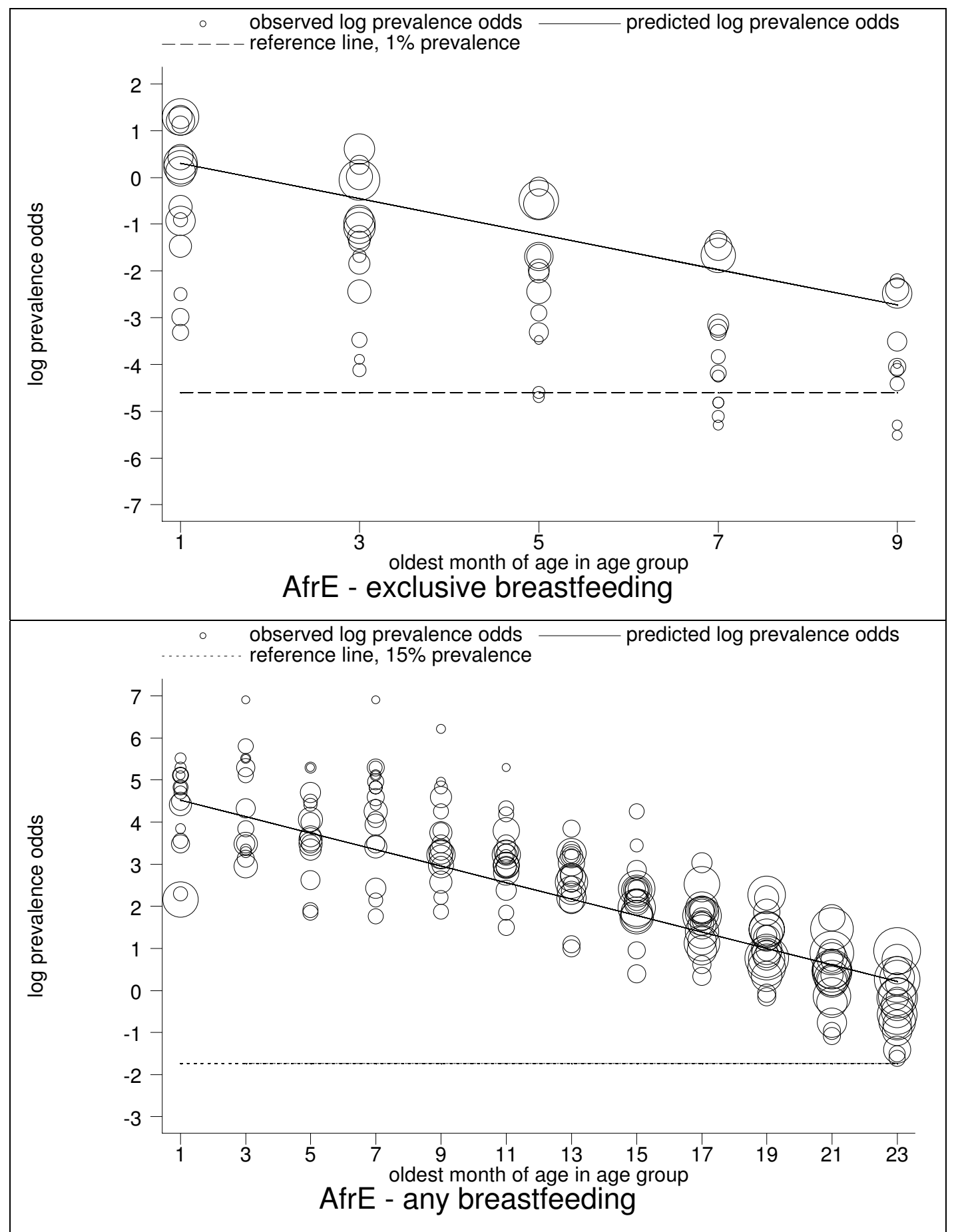

Figure 2

Estimated age trends for exclusive breastfeeding and for any breastfeeding in AfrE (Africa: very-high-adult, high-child-mortality stratum). Exclusive breastfeeding (upper panel, $n=66$ ), any breastfeeding (lower panel, $n=304$ ). 


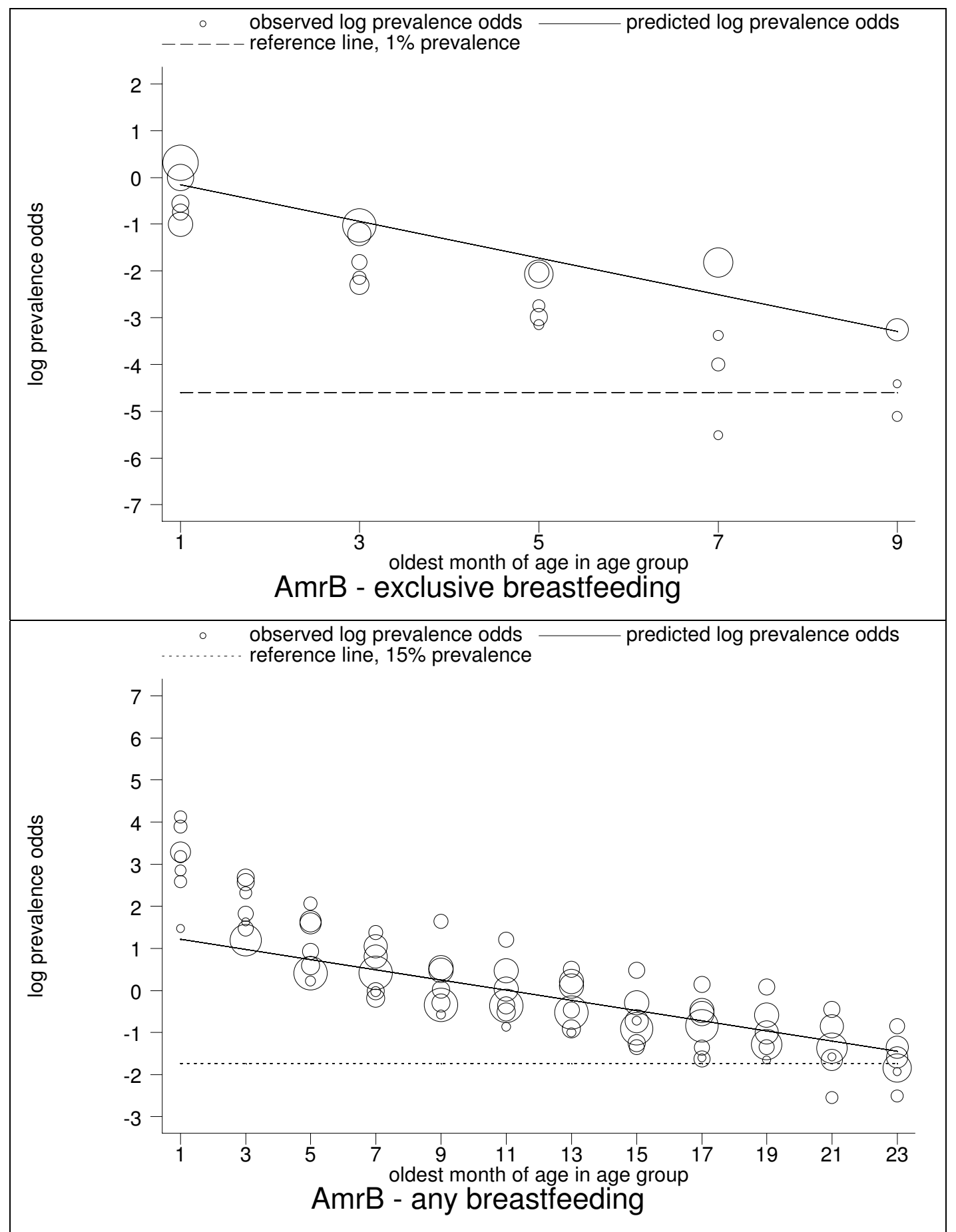

Figure 3

Estimated age trends for exclusive breastfeeding and for any breastfeeding in AmrB (Americas: low-adult, low-child mortalitystratum). Exclusive breastfeeding (upper panel, $n=22$ ), any breastfeeding (lower panel, $n=117$ ). 


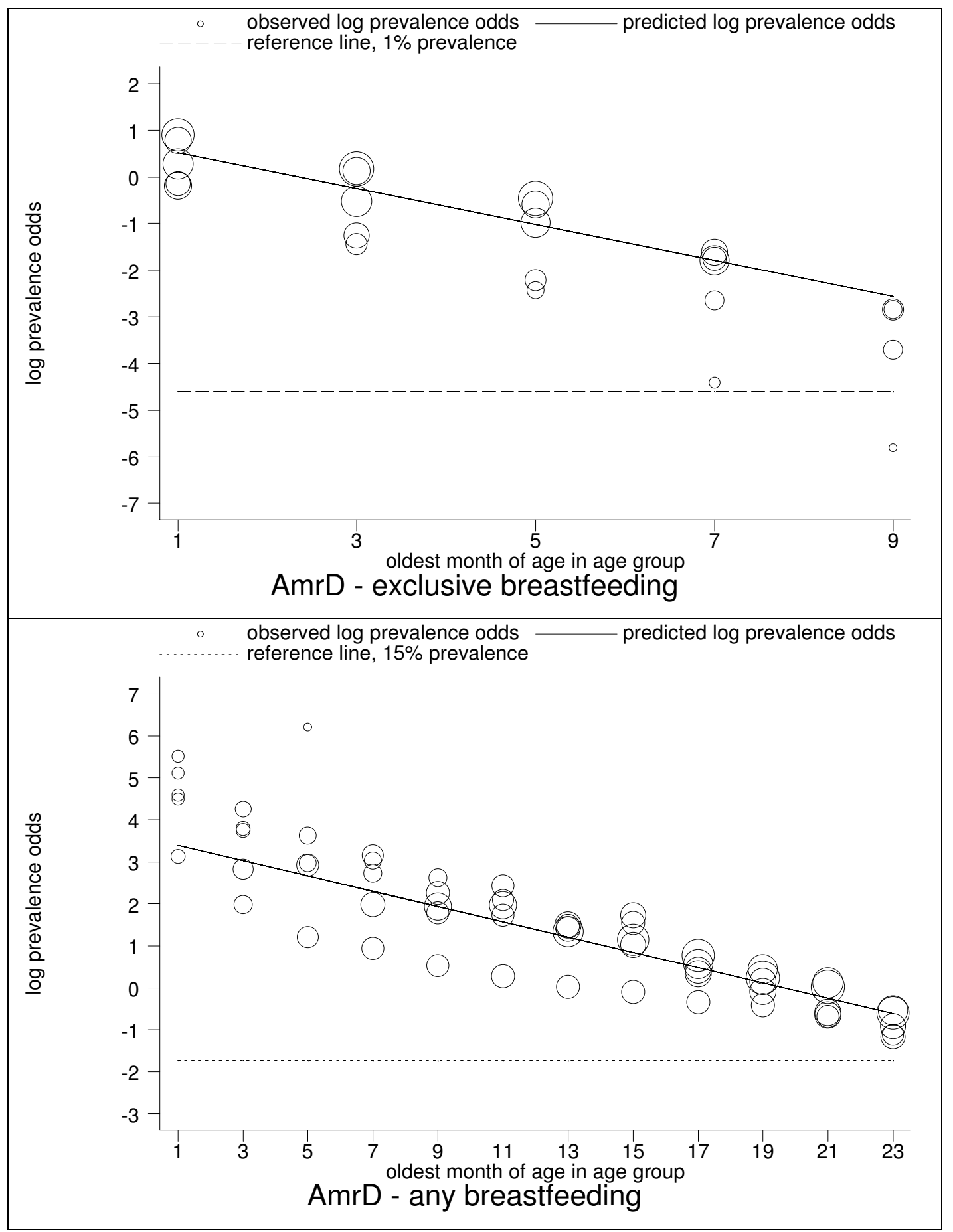

Figure 4

Estimated age trends for exclusive breastfeeding and for any breastfeeding in AmrD (Americas: high-adult, high-child mortality stratum). Exclusive breastfeeding (upper panel, $n=24)$, any breastfeeding (lower panel, $n=89$ ). 


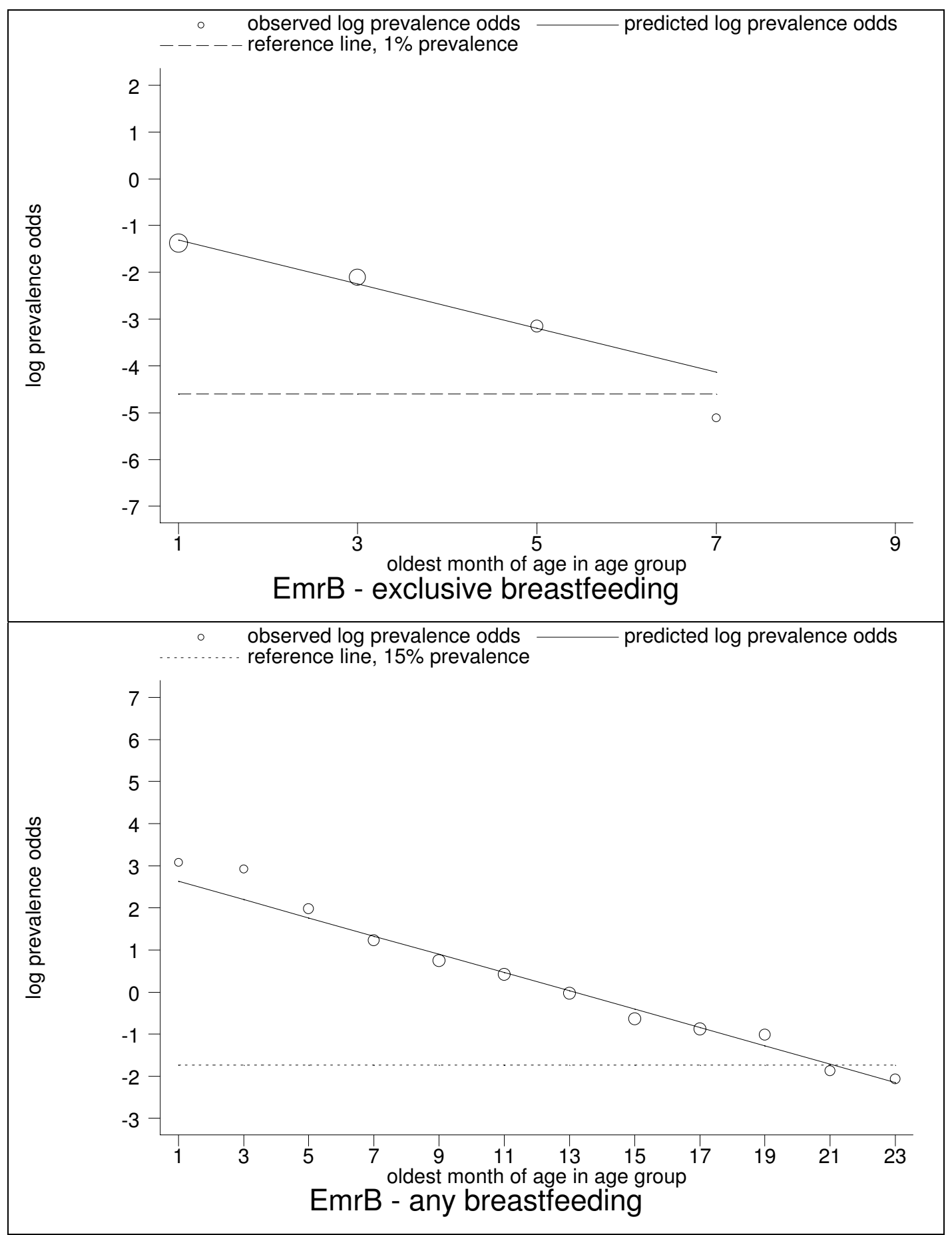

\section{Figure 5}

Estimated age trends for exclusive breastfeeding and for any breastfeeding in EmrB (Eastern Mediterranean: low-adult, lowchild-mortality stratum). Exclusive breastfeeding (upper panel, $n=4)$, any breastfeeding (lower panel, $n=18$ ). 


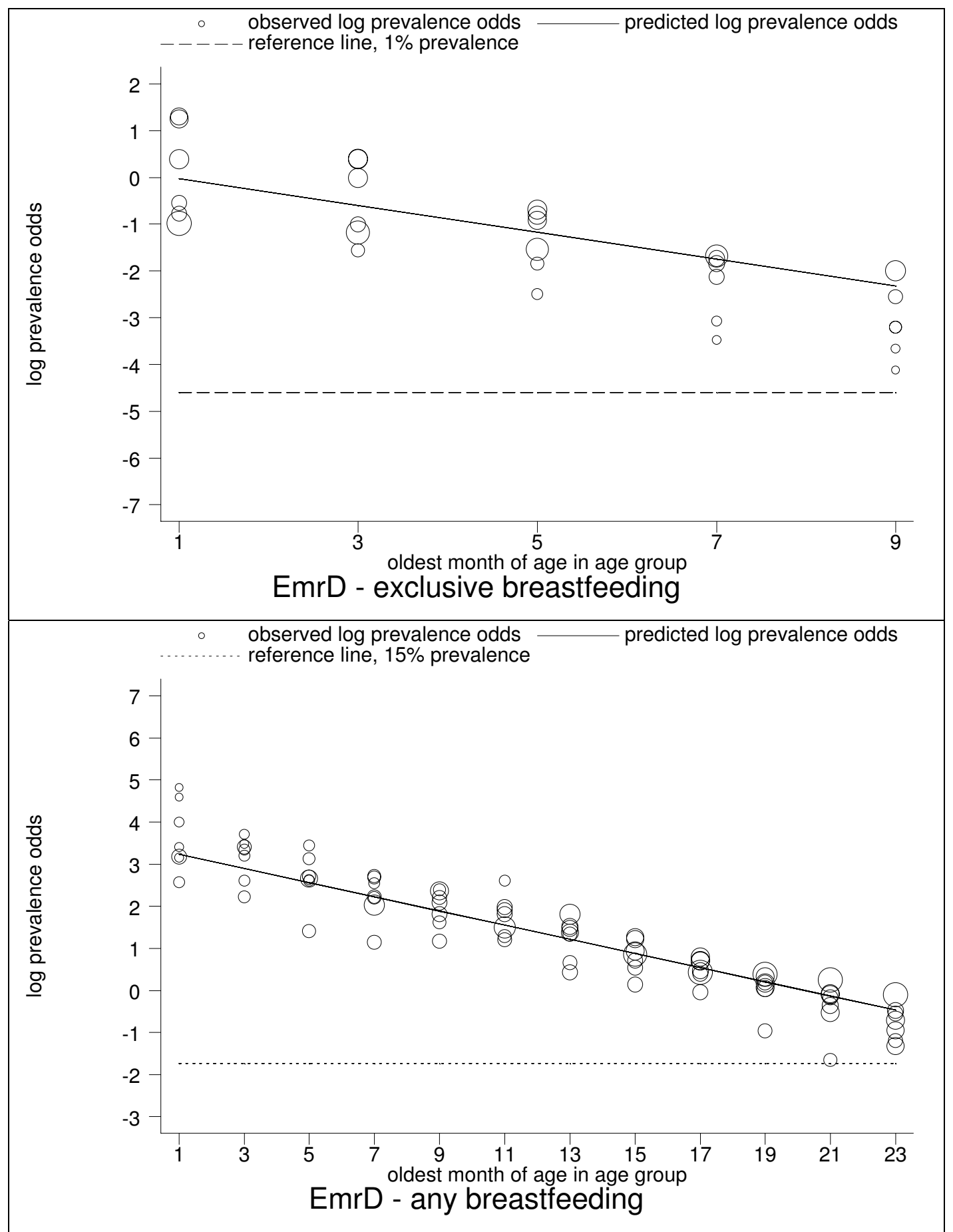

\section{Figure 6}

Estimated age trends for exclusive breastfeeding and for any breastfeeding in EmrD (Eastern Mediterranean: high-adult, highchild-mortality stratum). Exclusive breastfeeding (upper panel, $n=30$ ), any breastfeeding (lower panel, $n=125$ ). 


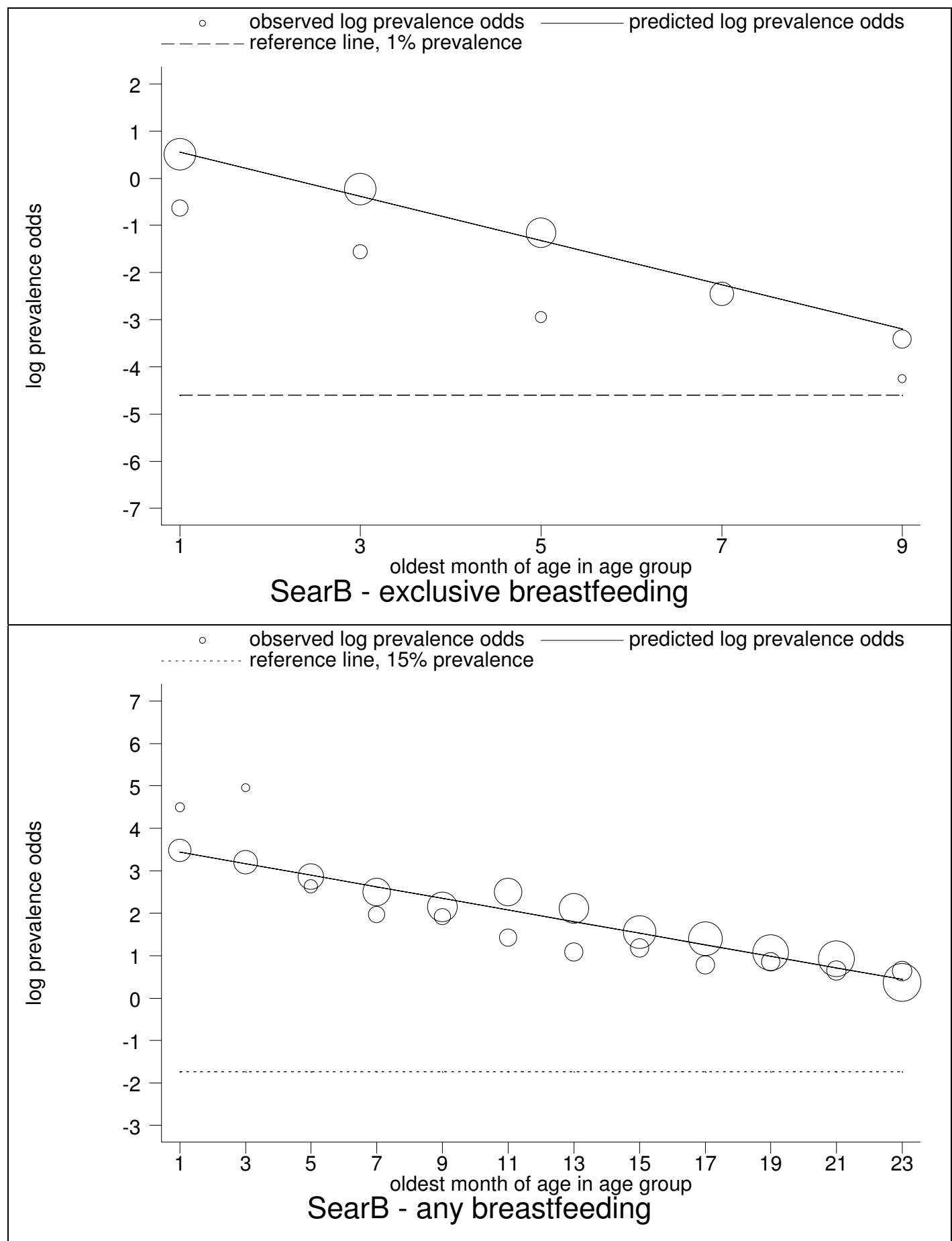

\section{Figure 7}

Estimated age trends for exclusive breastfeeding and for any breastfeeding in SearB (South-east Asia: low-adult, low-child-mortality stratum). Exclusive breastfeeding (upper panel, $n=9$ ), any breastfeeding (lower panel, $n=36$ ). 


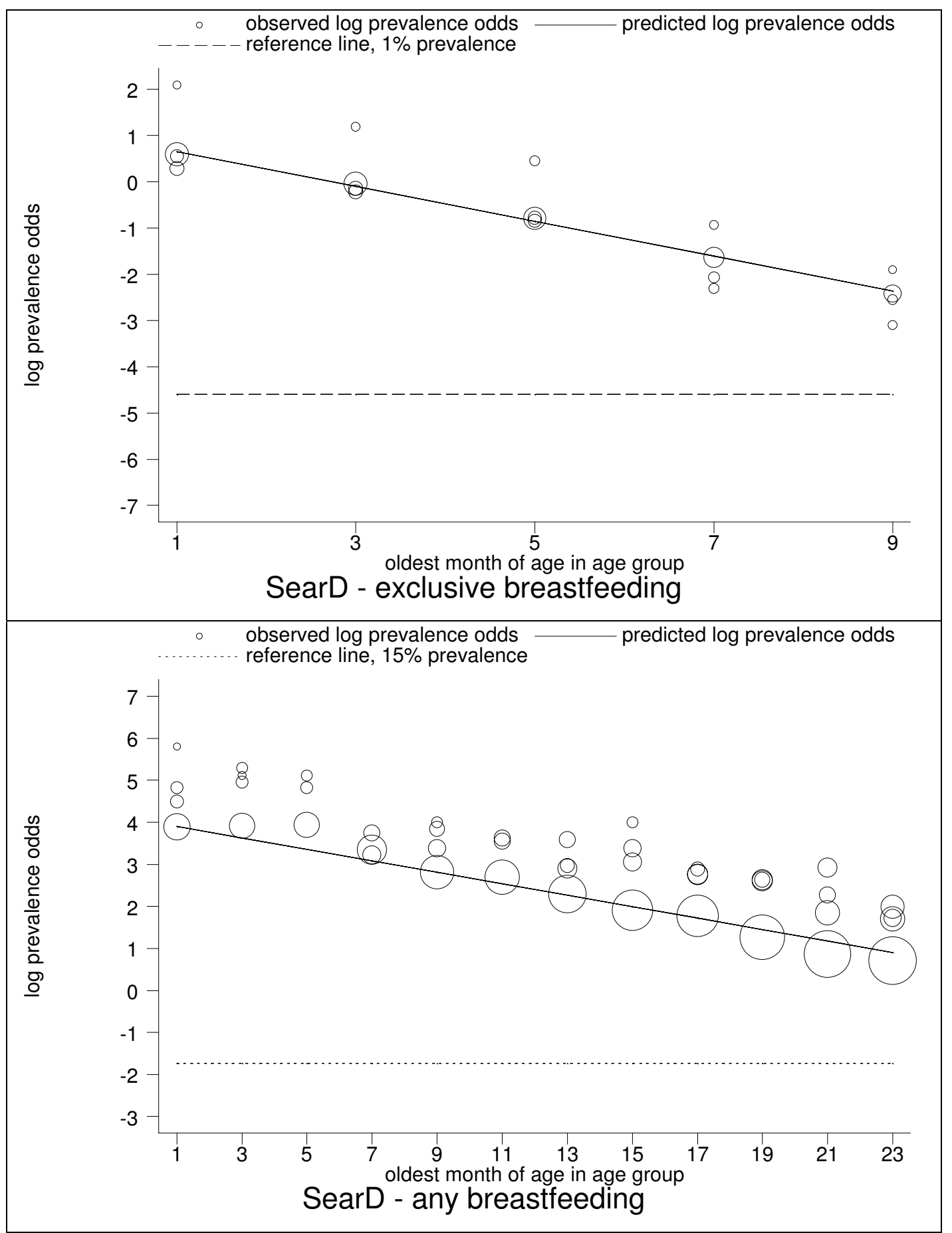

\section{Figure 8}

Estimated age trends for exclusive breastfeeding and for any breastfeeding in SearD (South-east Asia: high-adult, high-childmortality stratum). Exclusive breastfeeding (upper panel, $n=20$ ), any breastfeeding (lower panel, $n=69$ ). 


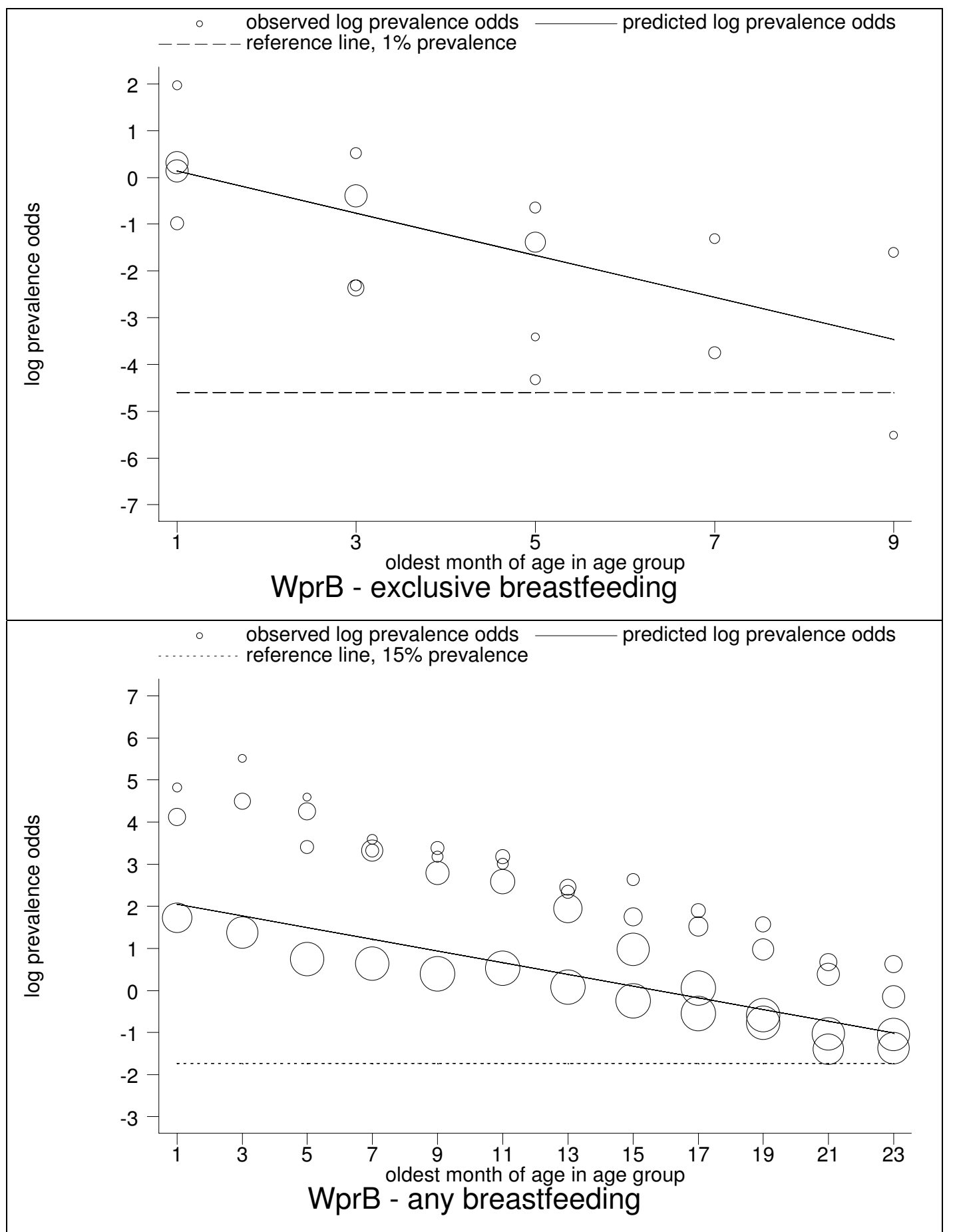

\section{Figure 9}

Estimated age trends for exclusive breastfeeding and for any breastfeeding in WprB (Western Pacific: low-adult, low-child-mortality stratum). Exclusive breastfeeding (upper panel, $n=16$ ), any breastfeeding (lower panel, $n=70$ ). 


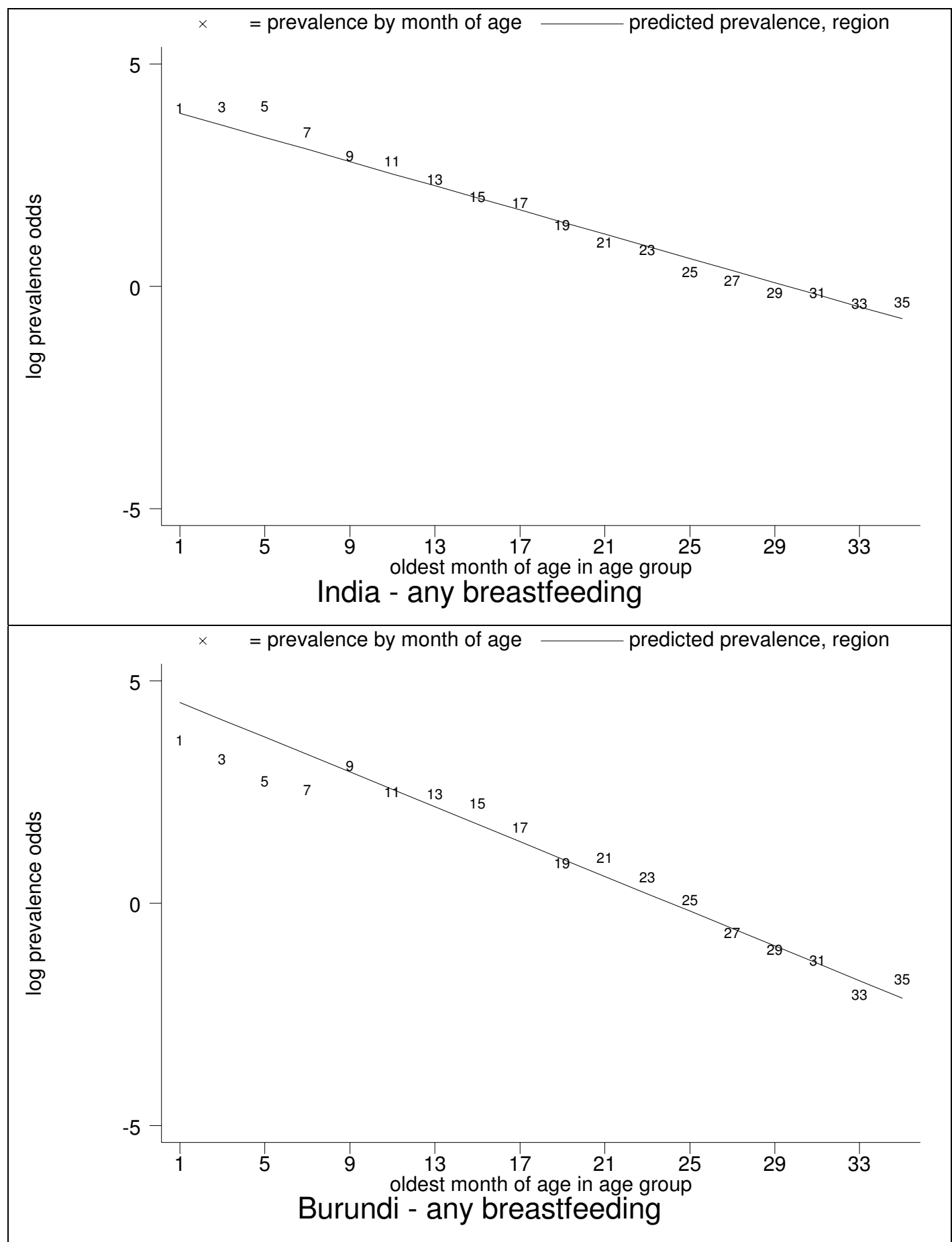

\section{Figure 10}

Examples of good predictive performance for India (upper panel) and Burundi (lower panel). Data markers show oldest month of age for the observati on. The patterns are typical for many developing countries. 


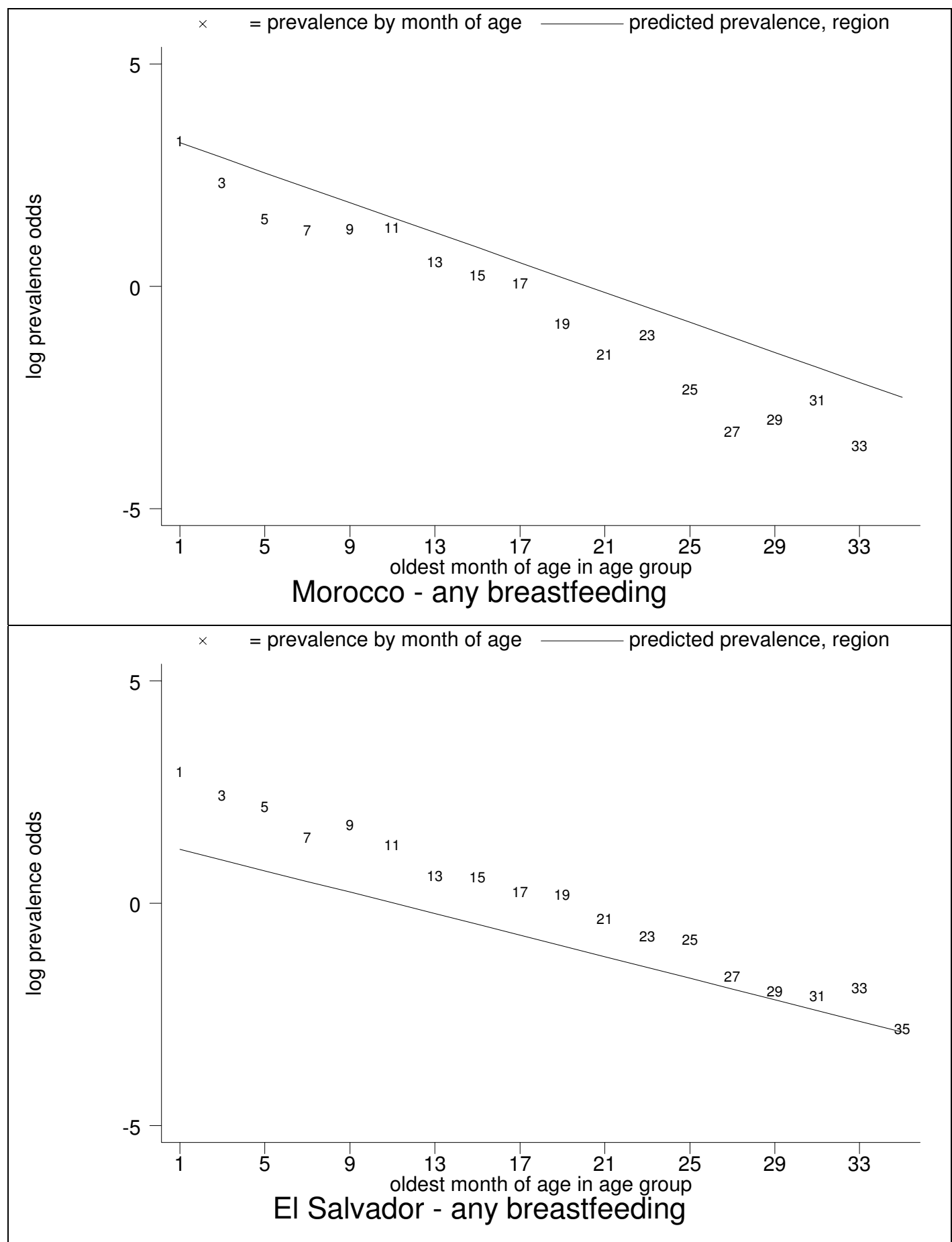

Figure I I

Examples of systematic over- (Morocco, upper panel) and under- (El Salvador, lower panel) prediction. Data markers show oldest month of age for the observation. The patterns are typical for many developing countries. 


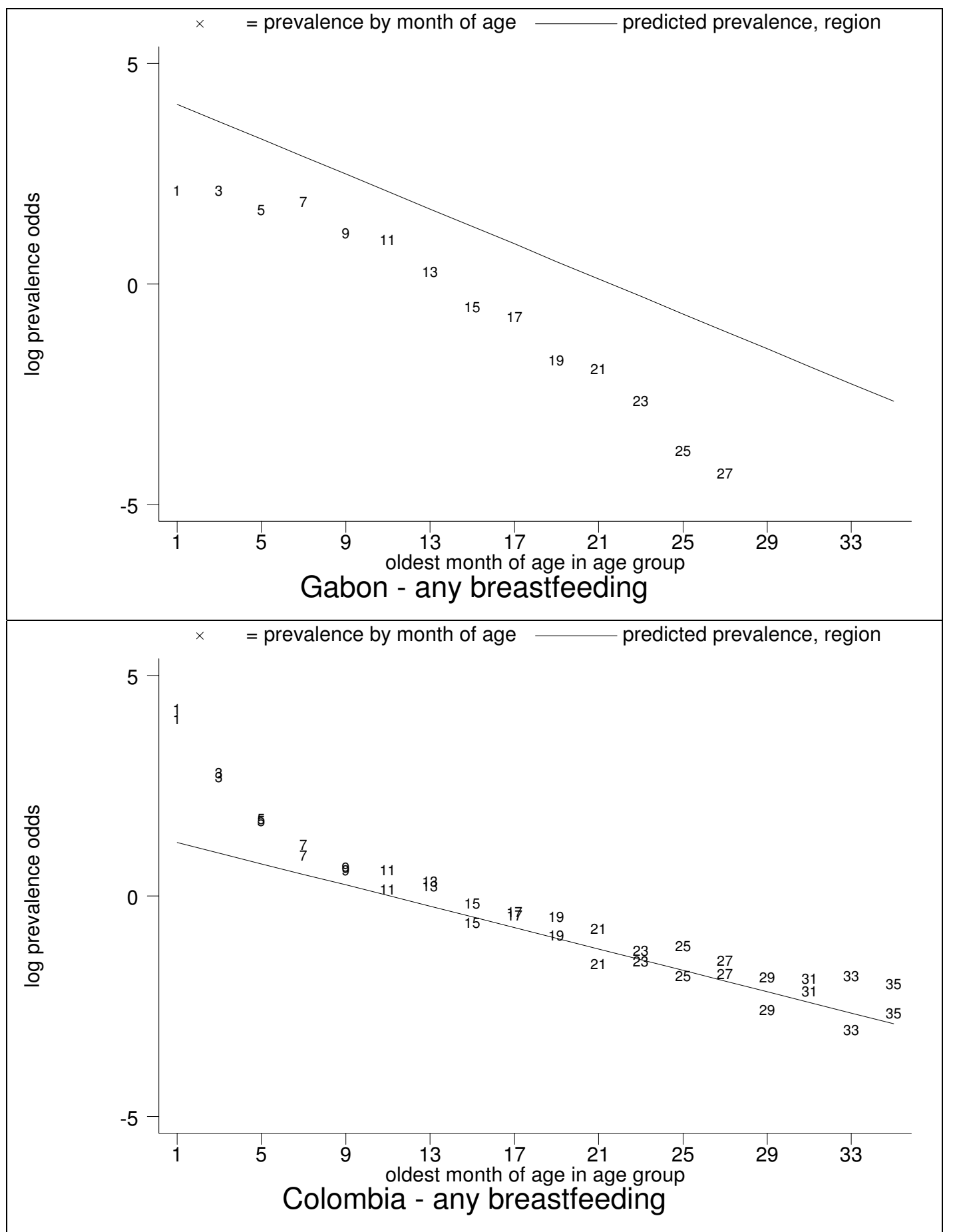

Figure 12

Examples of systematic non-linearity: concave (Gabon, upper panel); convex (Colombia, younger age groups, lower panel). Data markers show oldest month of age for the observation. Only a few developing countries display these patterns. 


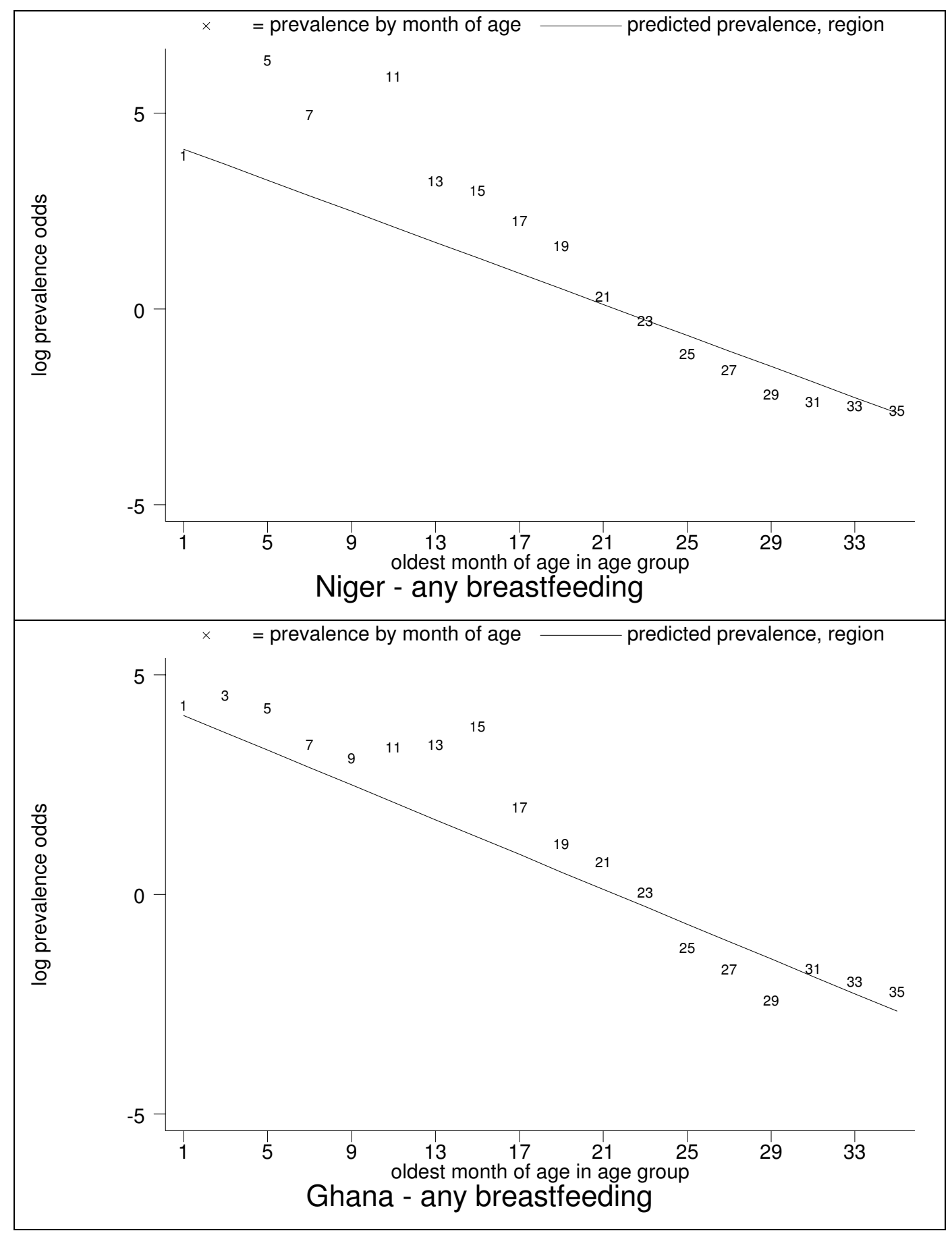

\section{Figure 13}

Examples of probable measurement error: especially months of age five and II (Niger, upper panel) and II, I3 and I5 (Ghana, lower panel). Data markers show oldest month of age for the observation. High variability could be due to limitations of 24hour recall, but consistently high age-specific values suggest systematic measurement error. 


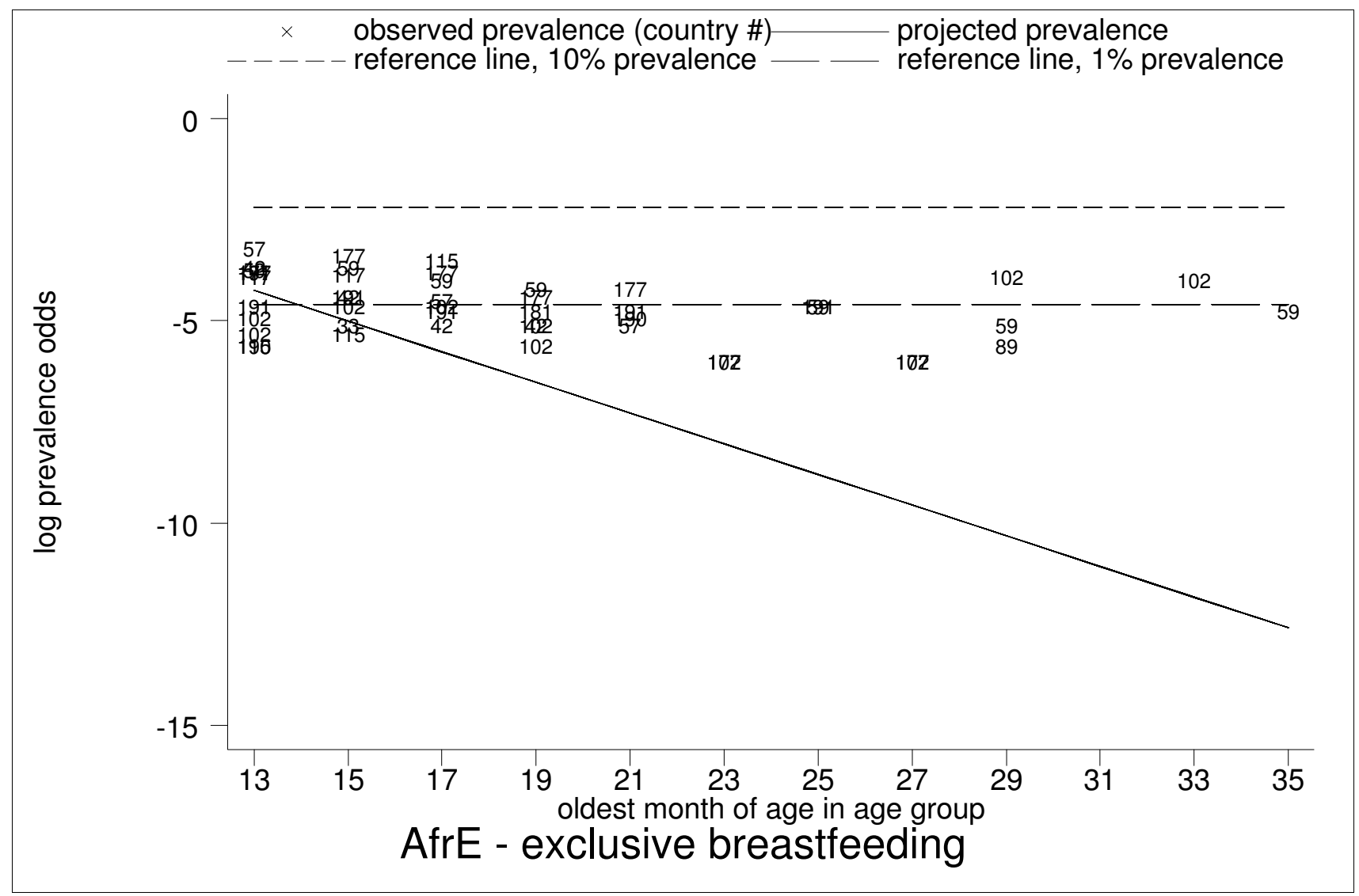

\section{Figure 14}

Projected and observed exclusive breastfeeding for age groups 12-13 to 34-35 months of age, with reference lines of $10 \%$ (short dashes) and I\% (long dashes) prevalence in AfrE. Low but non-zero observed rates of exclusive breastfeeding throughout second and third year of childhood in AfrE, with persistent rates of about 1\%, show limitations of 24-hour recall. This pattern is also typical for AmrB, AmrD, SearB and SearD (EmrB had no observations of exclusive breastfeeding during the second and third year of childhood).

specify '(not even water)', since the instructions are not part of the question itself, information on the consumption of water may not be systematically elicited. Moreover, since the 24-hour-recall module is implemented only for infants who are not reported to be given 'breast only', there is no mechanism for the identification of false positives. A more valid approach is used in UNICEF's MICS surveys, in which 24-hour recall is performed for all infants, regardless of whether or not they are reported to be given 'breast only'. Our own experience is that unless mothers are specifically asked about water and herbal teas, they will report that they gave only breast milk because water and teas are not perceived as foods (CGV, personal communication).

\section{Systematic measurement error}

We highlight the presence of anomalous observations of exclusive breastfeeding among older children in categoryA data (see Figures 14, 15, 16, 17), and interpret these results as providing evidence of measurement error resulting in systematic over-reporting in DHS surveys for exclusive and possibly other breastfeeding categories. In our view, while these findings have clear implications for the validity of observations of exclusive breastfeeding in DHS data at all age groups, the interpretation must take account of differences between regions and countries (see Figures 14, 15, 16, 17), perhaps due to differing perceptions about infant-and-child feeding practices. However, the anomalies detected become obvious only at older ages, and there are valid reasons why a small percentage of 


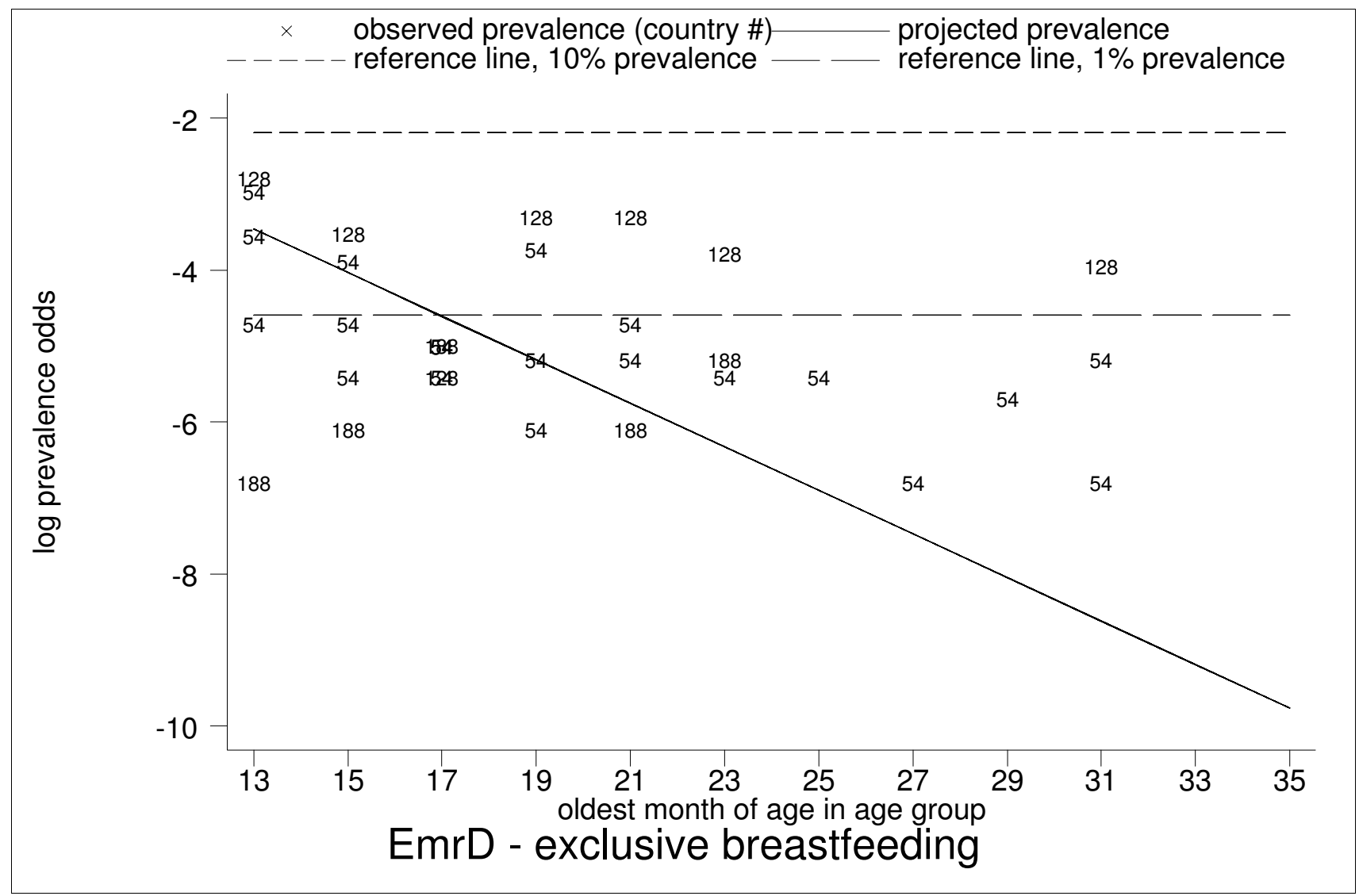

\section{Figure 15}

Projected and observed exclusive breastfeeding for age groups 12-13 to 34-35 months of age, with reference lines of $10 \%$ (short dashes) and I\% (long dashes) prevalence in EmrD. Observed non-zero exclusive breastfeeding rates throughout second and third year of childhood in EmrD, in particular observed rates of nearly $5 \%$ in Pakistan (code $=128)$ and Egypt (code $=54$, multiple surveys) for age groups $12-13$ to 16-17 months of age, suggest systematic measurement error. High overall variability show limitations of 24-hour recall.

older children may be exclusively breastfed on a given day (for example, illness of child or no food in the house). However, exclusive breastfeeding rates in some countries (particularly in the regions $\mathrm{AfrD}, \mathrm{EmrD}$ and WprB) display patterns that probably could not be completely explained in this manner. While the true explanation may remain unknown in the absence of further validation studies, it seems plausible that misunderstanding on the part of survey respondents or interviewers, or validity problems with the survey instrument beyond the limitations of 24-hour recall, are important contributing factors.

\section{Implications for exposure assessment}

Validity problems in DHS surveys have implications for the measurement of the whole distribution of exposure to suboptimal breastfeeding, especially for infants $\leq 6$ months of age. If the exposure baseline (that is, the group at no increased risk) is not validly measured, it is likely that classifications of low or intermediate risk (for example, the category predominant breastfeeding) are similarly underestimates of true risk. Conversely, it is unlikely that infants classified as at low, intermediate or high-risk are in fact at no, low or intermediate risk.

\section{Conclusions}

The size of the gap between breastfeeding practice and recommendations in developing countries is striking. More attention should be given to increasing breastfeeding, especially exclusive breastfeeding, and to monitoring trends. 


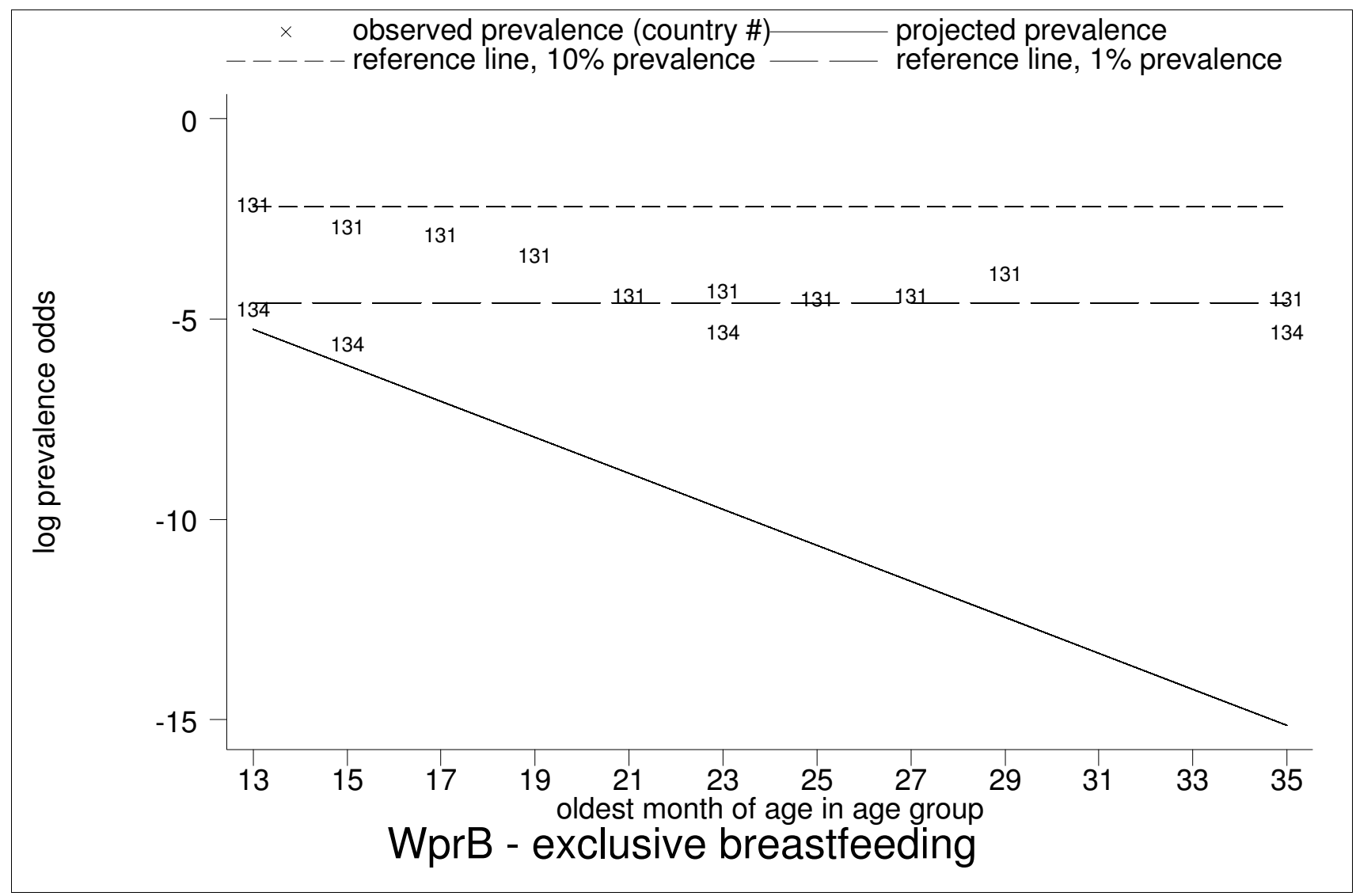

\section{Figure 16}

Projected and observed exclusive breastfeeding for age groups 12-13 to 34-35 months of age, with reference lines of $10 \%$ (short dashes) and I\% (long dashes) prevalence. Data markers show country code for the observation. Persistent non-zero exclusive breastfeeding rates in WprB throughout second and third year of childhood, in particular observed rates of about $10 \%$ in Papua New Guinea (code = I31, age groups 12-13 to 16-17 months of age), suggest systematic measurement error.

The introduction of more standardized and better validated survey instruments would be a valuable addition to child health monitoring. However, while existing data on breastfeeding are not perfect, in view of their extensive coverage, completeness and comprehensiveness, global exposure assessment is relatively robust. Although most data used here are category A, inclusion of category-B data allows for a more complete assessment in developing countries, especially among infants and in Africa.

C-ategory-A data present anomalies suggesting the limitations of current survey methods and the presence of systematic measurement error. Nevertheless, the regularity and consistency of observed patterns of breastfeeding (see Figures $1,2,3,4,5,6,7,8,9,10,11)$ support the view that existing data capture the effects of real biological and social processes. More studies of the sort done by Aarts and colleagues [21] are probably necessary for a full understanding to emerge of measurement error and validity problems in breastfeeding surveys.

While the random-effects model yields a valid expression of statistical error, measurement and model error - essentially unquantifiable here - are larger by probably an order of magnitude or more. On balance, we believe our estimates must be interpreted as conservative (that is, lower-bound) estimates of exposure to suboptimal breastfeeding, especially non-exclusive breastfeeding, among children in developing countries. To our knowledge, these 


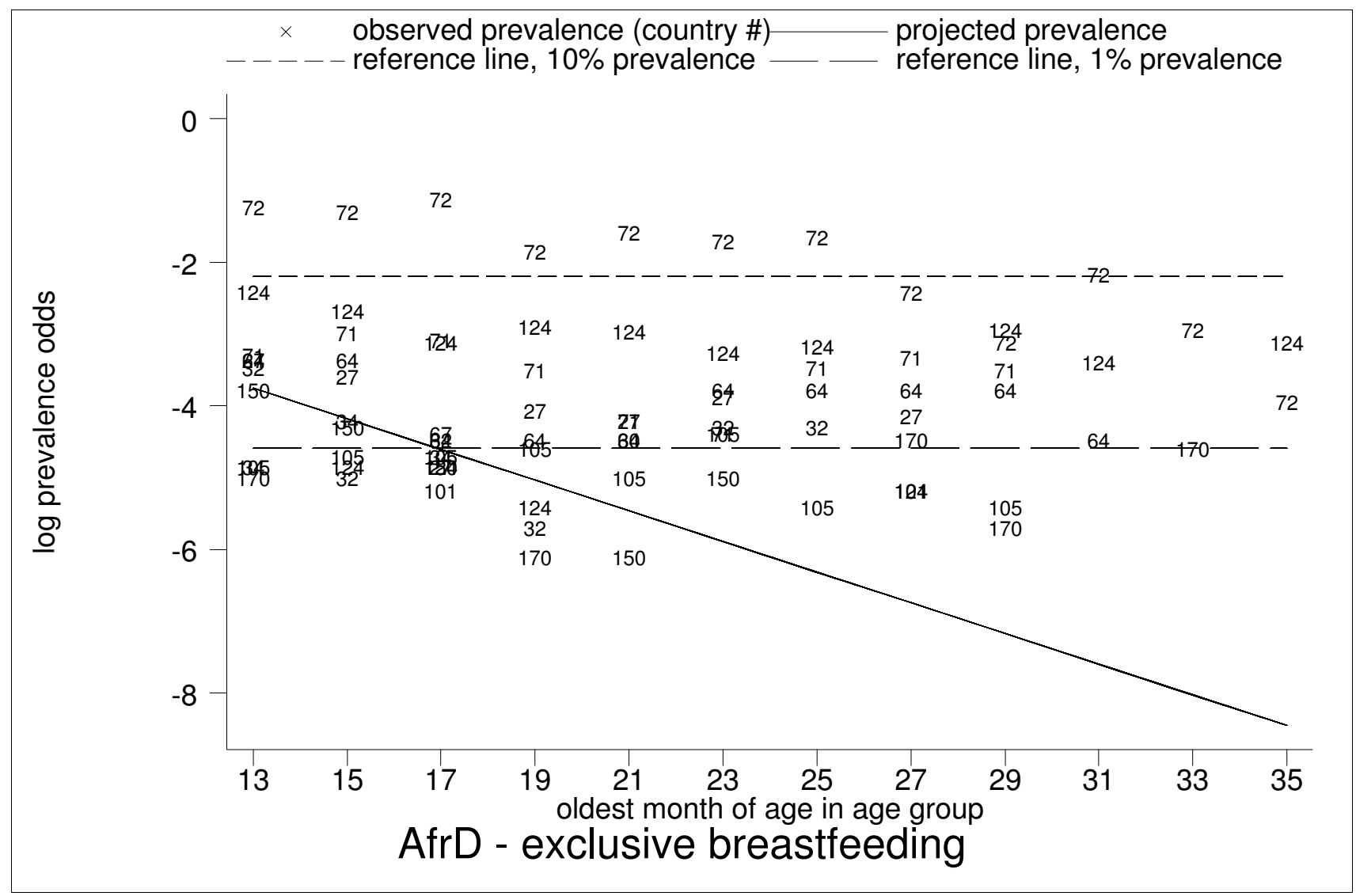

\section{Figure 17}

Projected and observed exclusive breastfeeding for age groups 12-13 to 34-35 months of age, with reference lines of $10 \%$ (short dashes) and I\% (long dashes) prevalence. High observed rates of exclusive breastfeeding throughout second and third year of childhood in AfrD, in particular, rates of 15-20\% in Guinea-Bissau (code $=72$ ) throughout second year of childhood and over $5 \%$ throughout third year, and persistent rates of nearly $5 \%$ in Nigeria (code $=124$, multiple surveys) and Guinea $($ code $=7 \mathrm{I}$ ), suggest systematic measurement error.

are the first published global estimates reporting exclusive breastfeeding rates for the infant population $\leq 6$ months of age [25-27].

Our method for the analysis of breastfeeding rates provides a potent tool for summarizing trends, validating observations, translating and extrapolating indicators (as well as projecting and imputing estimates when necessary) and should support more effective child health monitoring.

\section{Competing interests}

None declared.

\section{Abbreviations}

AfrD (Africa: high-adult, high-child-mortality stratum)

AfrE (Africa: very-high-adult, high-child-mortality stratum)

AmrB (Americas: low-adult, low-child mortality-stratum)

AmrD (Americas: high-adult, high-child mortality stratum)

DHS (Demographic and Health Surveys) 


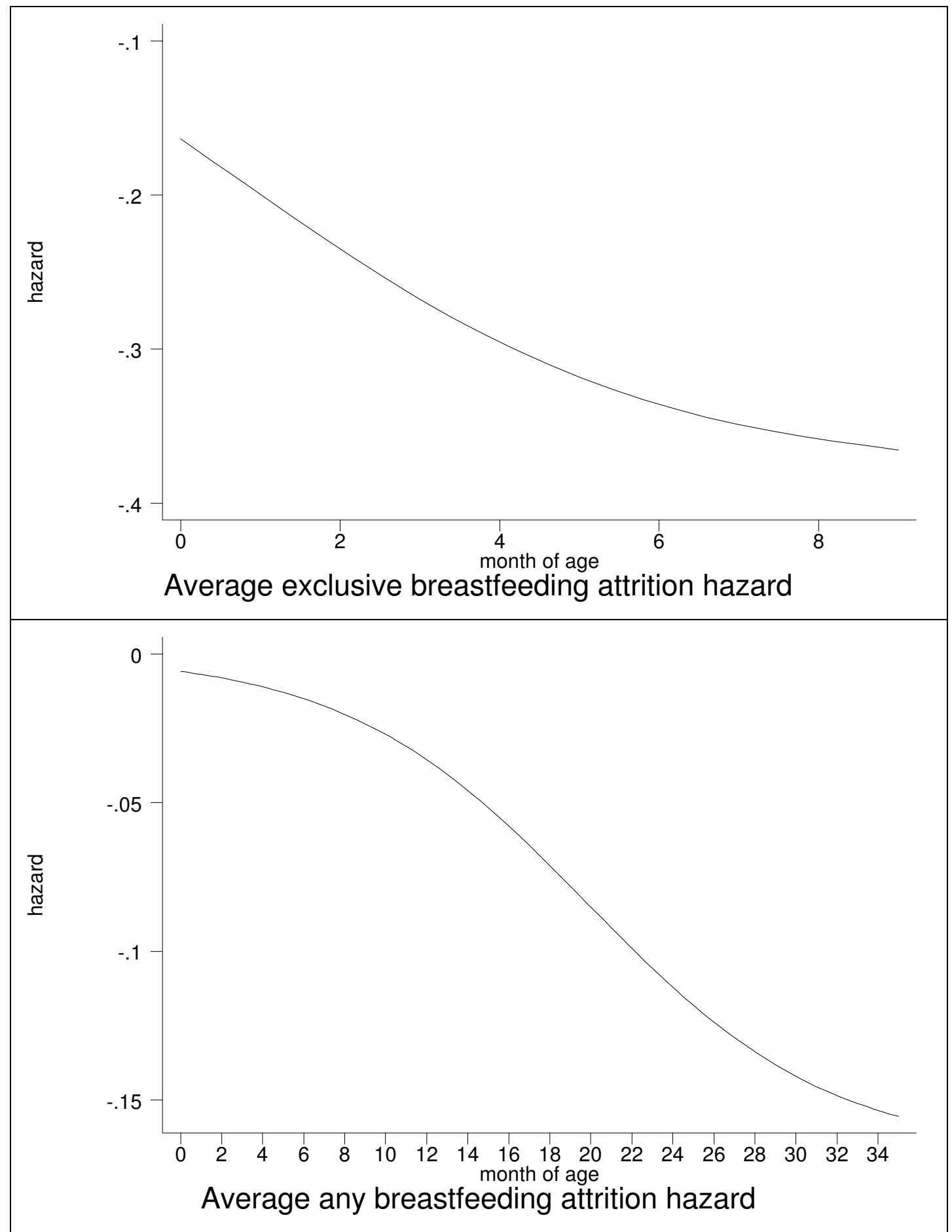

Figure 18

Age-specific attrition hazards for exclusive (upper panel) and any (lower panel) breastfeeding. 
EmrB (Eastern Mediterranean: low-adult, low-child-mortality stratum)

EmrD (Eastern Mediterranean: high-adult, high-childmortality stratum)

HIV (human immunodeficiency virus)

MICS (multiple indicators cluster surveys)

SearB (South-east Asia: low-adult, low-child-mortality stratum)

SearD (South-east Asia: high-adult, high-child-mortality stratum)

\section{WHO (World Health Organization)}

WprB (Western Pacific: low-adult, low-child-mortality stratum)

\section{UN (United Nations)}

UNICEF (United Nations Children's Fund)

\section{Authors' contributions}

JAL devised the analysis methods and drafted the manuscript. APB conceived of the study, collected and collated survey data, participated in interpretation of results and drafted key sections of the manuscript. CGV drafted key sections of the manuscript, participated in interpretation of results and revised the manuscript for essential intellectual content. MdO assisted with collection and interpretation of survey data and revised the manuscript for essential intellectual content. AJDB participated in development and interpretation of statistical methods. All authors revised and approved the final manuscript.

\section{Additional material}

\section{Additional File 1}

Prevalence NBF.Annex.doc (MS Word file in landscape format) is a table listing the data sources used for reported indicators.

Click here for file

[http://www.biomedcentral.com/content/supplementary/1741-

7015-2-26-S1.doc]

\section{Acknowledgements}

The authors wish to thank reviewers Laura Caulfield, Edward A. Frongillo, Jr., and Alan S. Ryan for helpful comments. The views expressed are solely those of the authors and do not necessarily reflect the decisions or stated policy of the Federal University of Pelotas or the World Health Organization.

\section{References}

I. Kramer MS, Kakuma R: The optimal duration of exclusive breastfeeding: a systematic review (WHO/NHD/0I.08) Geneva, Switzerland: World Health Organization; 2002.

2. Fifty-fourth World Health Assembly (Geneva, I4-I7 May 2001) Resolution WHA54.2: Infant and young child nutrition (WHA54.2) 2001 [http://www.who.int/gb/ebwha/pdf files/WHA54/ea54r2.pdf]. Geneva, Switzerland: World Health Organization

3. WHO: The optimal duration of exclusive breastfeeding: report of an expert consultation, Geneva, Switzerland, 28-30 March 200I (WHO/NHD/ 01.09) Geneva, Switzerland: World Health Organization; 2002.

4. Murray CJ, Ezzati M, Lopez AD, Rodgers A, Vander Hoorn S: Comparative quantification of health risks: conceptual framework and methodological issues. Popul Health Metr 2003, I: I

5. WHO: Indicators for assessing breast-feeding practices (WHO/CDD/SER/ 9I.14) Geneva, Switzerland: World Health Organization; 199I.

6. WHO, UNICEF: Global strategy for infant and young child feeding Geneva, Switzerland: World Health Organization; 2003.

7. Newell ML: Prevention of mother-to-child transmission of HIV: challenges for the current decade. Bul World Health Organ 2001, 79: I|38-I|44.

8. Demographic and health surveys: Providing information for informed decisions in population, health and nutrition. [http:/ /www.measuredhs.com].

9. UNICEF: Monitoring the situation of children and women. [http://www.childinfo.org].

10. United Nations: World Population Prospects: the 2000 Revision New York: United Nations Department of Economic and Social Affairs, Population Division; 200I.

II. WHO: The world health report 2002: reducing risks, promoting healthy life Geneva, Switzerland: World Health Organization; 2002.

12. Salomon JA, Murray CJL: The epidemiologic transition revisited: compositional models for causes of death by age and sex. Populand Dev Rev 2004, 28:205-228.

13. Murray CJ, Ferguson BD, Lopez AD, Guillot M, Salomon JA, Ahmad $O B$ : Modified logit life table system: principles, empirical validation, and application. Population Studies 2003, 57: I65-I82.

14. Aldrich JH, Nelson FD: Linear probability, logit, and probitmodels. In Quantitative Applications in the Social Sciences, No. 07-045 Edited by: Lewis-Beck MS. Beverly Hills, California, USA: Sage Publications; 1984.

15. Greenland S: Introduction to regression models. In Modern Epidemiology 2 nd edition. Edited by: Rothman KJ, Greenland S. Philadephia, Pennsylvania, USA: Lippincott Williams and Wilkins; 1998:359-399.

16. Armitage P, Berry G, Matthews JNS: Modelling categorical data. In Statistical methods in medical research 4th edition. Oxford, England: Blackwell; 2002:485-502.

17. Piwoz EG, Creed de Kanashiro H, Lopez de Romaña G, Black RE, Brown KH: Potential for misclassification of infants' usual feeding practices using 24-hour dietary assessment methods. J Nutr 1995, I 25:57-65.

18. Morrow AL, Guerrero ML, Shults J, Calva JJ, Lutter C, Bravo J, RuizPalacios G, Morrow RC, Butterfoss FD: Efficacy of home-based peer counselling to promote exclusive breastfeeding: a randomised controlled trial. Lancet 1999, 353:|226-1231.

19. Haider R, Ashworth A, Kabir I, Huttly SR: Effect of communitybased peer counsellors on exclusive breastfeeding practices in Dhaka, Bangladesh: a randomised controlled trial. Lancet 2000, 356: I643-1647.

20. Boerma JT, Sommerfelt AE: An assessment of the quality of breast-feeding data in DHS-I surveys Calverton, Maryland, USA: Macro International; 1993.

21. Aarts C, Kylberg E, Hornell A, Hofvander Y, Gebre-Medhin M, Greiner T: How exclusive is exclusive breastfeeding? A comparison of data since birth with current status data. Int J Epidemiol 2000, 29:104I-1046.

22. Victora CG, Smith PG, Vaughan JP, Nobre LC, Lombardi C, Teixeira AM, Fuchs SM, Moreira LB, Gigante LP, Barros FC: Evidence for protection by breast-feeding against infant deaths from infectious diseases in Brazil. Lancet 1987, 2:319-322.

23. Brown KH, Black RE, Lopez de Romaña G, Creed de Kanashiro H: Infant feeding practices and their relationship with diarrhoeal and other diseases in Huascar (Lima), Peru. Pediatrics |989, 83:3|-40. 
24. Arifeen SE, Black RE, Antelman G, Baqui AH, Caulfield LE, Becker S: Exclusive breastfeeding reduces acute respiratory infection and diarrhea deaths among infants in Dhaka slums. Pediatrics 200I, 108:E67.

25. WHO: Global data bank on breast-feeding. Breast-feeding: the best start in life (WHO/NUT/96.I) Geneva, Switzerland: World Health Organization; 1996.

26. WHO: Complementary feeding of young children in developing countries: a review of current scientific knowledge (WHO/NUT/98.I) Geneva, Switzerland: World Health Organization; 1998:137.

27. Betrán AP, de Onís M, Lauer JA, Villar J: Ecological study of effect of breast feeding on infant mortality in Latin America. BMJ 200I, 323:303-306.

\section{Pre-publication history}

The pre-publication history for this paper can be accessed here:

http://www.biomedcentral.com/1741-7015/2/26/prepub

Publish with Bio Med Central and every scientist can read your work free of charge

"BioMed Central will be the most significant development for disseminating the results of biomedical research in our lifetime. "

Sir Paul Nurse, Cancer Research UK

Your research papers will be:

- available free of charge to the entire biomedical community

- peer reviewed and published immediately upon acceptance

- cited in PubMed and archived on PubMed Central

- yours - you keep the copyright

Submit your manuscript here:

http://www.biomedcentral.com/info/publishing_adv.asp
BioMedcentral 